\title{
YERBILIMLERI
}

Bulletin for Earth Sciences

Yerbilimleri, 2020, 41 (2), 85-120, DOI:10.17824/yerbilimleri.889227

Hacettepe Üniversitesi Yerbilimleri Uygulama ve Araştırma Merkezi Bülteni

Bulletin of the Earth Sciences Application and Research Centre of Hacettepe University

\section{Karbonifer Pamuktaş Plütonu'nun petrografisi, jeokimyası ve petrolojik özellikleri, Bayburt (KD Türkiye)}

Petrography, geochemistry and petrological characteristics of the Carboniferous Pamuktaş Pluton, Bayburt (NE Turkey)

\author{
Mehmet Ali GÜCER ${ }^{1^{*}}$, Ekrem SARI ${ }^{2}$ \\ $1^{*}$ Gümüşhane Üniversitesi, Müh. ve Doğa Bil. Fak., Jeoloji Müh. Böl., Bağlarbaşı Mah., Merkez Gümüşhane \\ ${ }^{2}$ Yıldız Bakır Madencilik Sanayi A.Ş., Gümüşhane
}

Geliş (received): 1 Mart (March) 2021 Kabul (accepted): 9 Nisan (April) 2021

Öz

Doğu Pontidler (KD Türkiye), Anadolu Levhasının jeolojik olarak şekillenmesinde önemli bir rol oynayan Alp-Himalaya orojenezinin etkisi ile oluşmuş olup farklı türde magmatik kayaları içermesi bakımından önemli bir alan konumundadır. Özellikle Karbonifer plütonlar, doğu Pontidlerin güney kesiminde, daha geniş mostralar halinde ve daha yaygın olarak gözlenmektedir. Bu çalışma, Bayburt'un (KD Türkiye) Pamuktaş Köyü ve çevresinde yer alan granitik kayaçlar üzerinde yeni petrografik ve tüm kayaç jeokimyası verileri sunmaktadır. Ayrıca, bu kayaçların oluşumunda hâkim olan kaynak bölge, petrolojik süreçler ve jeodinamik ortam tartışılmaktadır. Yaklaşık 5 $\mathrm{km}^{2}$ 'lik bir alanı kapsayan Karbonifer Pamuktaş Plütonu, çalışma alanında Jura öncesi temeli temsil etmekte ve uyumsuz olarak Alt-Orta Jura volkanoklastik ve volkanik kayaçlar ile Üst Jura-Alt Kretase kireçtaşları tarafından örtülmektedir. Pamuktaş Plütonu esas olarak granit/granit porfir ve aplit (mikrogranit), daha az oranda ise granodiyorit ve kuvars mikrodiyorit türü kayaçlardan meydana gelmektedir.

https://doi.org/10.17824/yerbilimleri.889227

M.A. GÜCER maligucer@gmail.com

${ }^{1 *}$ Gümüşhane Üniv., Müh. ve Doğa Bil. Fak., Jeol. Müh. Böl., Bağlarbaşı Mah., Gümüşhane ORCID 0000-0002-9075-3350

${ }^{2}$ Yıldız Bakır Madencilik Sanayi A.Ş. Gümüşhane ORCID 0000-0003-1079-9226 
Granitik kayaçlar, özşekilli ve özşekilsiz granüler/mikrogranüler dokuya sahip olup başlıca alkali feldispat (ortoklas), plajiyoklas, kuvars, biyotit ve amfibol (hornblend) minerallerinden oluşur. Kayaçlar yüksek $\mathrm{SiO}_{2}$ içeriklerine (\%65.62-75.09) ve yüksek K'lu kalk-alkaliden şoşonitiğe kadar uzanan bir afiniteye sahip olup I-tipi bir kaynaktan itibaren türemiştir. Granitik kayaçlar peralümin karakterli olup çarpışma sonrası volkanik yay granitoyidleri ile benzerlik göstermektedir. Ana ve iz element trendleri, kayaçların oluşumunda plajiyoklas, hornblend, apatit ve Fe-Ti oksit mineral fraksiyonlaşmasının önemli rol oynadığını göstermektedir. Pamuktaş Plütonu'nun petrolojik özelliklerine göre, granitlerin gelişiminde fraksiyonel kristallenme, magma karışımı ve daha az oranda asimilasyon ve kısmi ergime işlemlerinin rol oynadığı ortaya konmuştur. Hesaplanan zirkon doygunluk sıcaklıkları $\left(730-844^{\circ} \mathrm{C}\right)$ düşük ilksel magma sıcaklıklarını yansıtmaktadır. Elde edilen tüm veriler Karbonifer Pamuktaş Plütonu'nun ana magmasının orta-alt kıtasal kabuk ve zenginleşmiş litosferik manto ergiyiklerinden kısmi ergime sonucu türediğini ve kıtasal magma odasında farklılaşarak yerleştiğini göstermektedir.

Anahtar Kelimeler: Pamuktaş (Bayburt), granitoyid, Doğu Pontidler, jeokimya, petroloji, magmatizma.

\section{ABSTRACT}

The Eastern Pontides (NE Turkey) that formed during the Alpine-Himalayan orogeny in which geologically plays an important role in the formation of Anatolian Plate, is a significant area in term of containing different igneous rocks. Especially Carboniferous plutons are widely observed in the southern part of the Eastern Pontides in larger outcrops and more commonly. This study presents new petrography and whole-rock geochemistry data on granitic rocks in the Pamuktaş area of Bayburt (NE Turkey). In addition, the source region of the magma, petrological processes and geodynamic setting prevailing in the formation of these granitic rocks are discussed. The Carboniferous Pamuktaş Pluton, which includes an area of approximately $5 \mathrm{~km}^{2}$, represents the pre-Jurassic basement in the study area and is unconformably overlain by Lower-Middle Jurassic volcanoclastic and volcanic rocks and Upper Jurassic-Lower Cretaceous limestones. Pamuktaş Pluton mainly consists of granite/granite porphyry and aplite (microgranite), to a lesser extent 
granodiorite and quartz microdiorite rocks. Granitic rocks mainly consist of alkali feldspar (orthoclase), plagioclase feldspar, quartz, biotite, and amphibole (hornblende) minerals, as having euhedral and anhedral granular/microgranular textures. The rocks have high $\mathrm{SiO}_{2}$ contents (65.62-75.09 wt.\%) and a high $\mathrm{K}$ calcalkali to shoshonitic affinities, and have been derived from an l-type source. The granitic rocks are peralumine in character and are similar to post-collisional volcanic arc granitoids. Major and trace element trends show that the plagioclase, hornblende, apatite, and Fe-Ti oxide mineral fractionations play an important role in the formation of rocks. According to the petrological properties of the Pamuktaş Pluton, it has been revealed that the fractional crystallization, magma mixing, and less assimilation and partial melting processes play a role in the development of granites. The calculated zircon saturation temperatures $\left(730-844^{\circ} \mathrm{C}\right)$ reflect lower initial magma temperatures. All obtained data suggest that the parental magma of the Carboniferous Pamuktaş Pluton has evolved from the mixing of lithospheric mantle and middle-lower crustderived melts as a result of partial melting, differentiated and emplaced in the continental magma chamber.

Keywords: Pamuktaş (Bayburt), granitoid, Eastern Pontides, geochemistry, petrology, magmatism.

\section{GiRiş}

Yerkürede kıtasal kabuk boyunca geniş bir dağılım sergileyen intrüzif kayaçlar bir bölgenin tektonomagmatik gelişiminin anlaşılmasında oldukça önemli ipuçları sağlamaktadır. Teknolojik gelişmelere paralel olarak, özellikle son yıllarda intrüzif kayaçların petrolojik özelliklerinin aydınlatılmasına yönelik yeni yöntemlerin gelişmesi, bu kayaçların oluşum ortamları ve mekanizmalarına ilişkin yeni modellerin ortaya çıkmasına olanak sağlamıştır.

Çalışma alanının da içerisinde yer aldığı Doğu Pontid Orojenik Kuşağı (KD Türkiye), Türkiye'nin jeolojik olarak şekillenmesinde önemli bir rol oynayan Alp-Himalaya orojenezinin etkisi ile oluşmuş olup farklı türde magmatik kayaçları içermesi bakımından önemli bir alan konumundadır. Karadeniz havzasının güneydoğu kıyısı boyunca yaklaşık 500 km uzunluğunda ve 100 km genişliğinde bir orojenik kuşağı 
meydana getiren bu bölge, Geç Mesozoyik sırasında kuzeye yiten okyanusal litosfer üzerinde gelişmiş ve iyi korunmuş bir ada yayı olarak bilinmektedir (ör., Akın, 1979; Şengör ve Yılmaz, 1981; Akıncı, 1984). Sakarya Zonu'nun doğu kısmını oluşturan Doğu Pontid Orojenik Kuşağında yüzeyleme veren Jura öncesi temel birimleri dört farklı tipte temsil edilmektedir (Okay ve Şahintürk, 1997). Bunlar: (i) Karbonifer öncesi yüksek dereceli metamorfik kayaçlar, (ii) Erken Karbonifer magmatik kayaçlar, (iii) Permo-Karbonifer sığ denizel-karasal sedimanlar ve (iv) Permo-Triyas metabazit-fillitmermer.

Doğu Pontid Orojenik Kuşağı Üst Kretase dönemde göstermiş olduğu farklılıklardan dolayı volkanik kayaçların daha yaygın gözlendiği kuzey zon ve sedimanter kayaçların hâkim olduğu güney zon olmak üzere iki farklı zona ayrılmış ve tanımlanmıştır (Güven, 1993). Doğu Pontidlerde Jura öncesi intrüzif kayaçlar genellikle Paleozoyik ile Senozoik arasında gelişmiş olmakla birlikte, değişen yaş, büyüklük ve kompozisyona sahiptir. Özellikle Karbonifer plütonlar daha büyük kütlelerde ve daha çok güney kesimde gözlenirken, daha küçük intrüzif kütleler halinde ve daha az oranda kuzey kesimde yüzeyleme vermektedir. Güney zonda yer alan Gümüşhane, Köse ve Akşar granitoyitleri başta olmak üzere PermoKarbonifer'den Eosen sonrasına kadar farklı bileşim, büyüklük ve yaş aralığında gelişmiş birçok intrüzif kütle yer almaktadır. Bu intrüzif kütlelerden genel jeoloji çalışmaları dışında petrokimyasal, petrolojik ve jeokronolojik çalışmaları yapılmamış başka intrüzif kütleler de bulunmaktadır. Bunlardan biri olan ve Akşar Granitoyidi'nin kuzey kesimini oluşturan Pamuktaş Plütonu (Bayburt, NE Türkiye) çalışma konusu olarak seçilmiş ve bu kapsamda petrografik, jeokimyasal ve petrolojik özellikleri irdelenmiştir.

\section{INCELEME ALANININ JEOLOJISi}

İnceleme alanı, Doğu Karadeniz Bölgesi, Bayburt il sınırları içerisinde, Akşar beldesi kuzeyinde bulunan Pamuktaş Köyü ve civarında yer almakta, Trabzon H-43-b2 pafta sınırları içerisinde bulunmaktadır.

Alpin orojenik kuşağı içerisinde bulunması nedeniyle gerek Alpin tektonik birliklerini gerekse daha yaşlı orojenik dönemleri temsil eden birimlerin yer aldığı Türkiye, farklı 
birçok tektono-stratigrafik birliğin bir araya gelmesi sonucu oluşmuştur. Anadolu levhasının jeolojik olarak şekillenmesi Tetis paleo okyanusların (Paleo-Tetis ve NeoTetis) değişik kollarının farklı zaman dilimlerinde açılıp kapanması ve buna paralel oluşan aktif/pasif kıta kenarı çökelleri ile yay ve sütur karmaşıklarından meydana gelen kıta parçalarının Tersiyer'de bir araya gelmesi ile olmuştur (Okay, 2008; Göncüoğlu, 2010). Aynı zamanda, daha eski orojenik dönemlere (Kadomiyen, Variskan, Kimmeriyen gibi) ait ürünler metamorfik masifler, magmatik kompleksler ve onları üzerleyen örtü birimleri şeklinde Alp-Himalaya orojenezine ait tektonik birliklerin tabanında yer alır. Doğu Pontid Orojenik Kuşağı olarak da bilinen Doğu Pontidler ise Sakarya Zonu'nun doğu kesimini oluşturmakta ve İzmir-AnkaraErzincan sütur zonunun kuzeyinde yer almaktadır (Okay ve Tüysüz, 1999).

Doğu Pontidler'in kuzey kesimleri boyunca kalk-alkalen volkanik kayaçlar ve bunların piroklastik kayaçları ile epiklastik birimler ve çoğunlukla granitik intrüzyonlar yaygın olarak gözlenmektedir (Arslan vd., 1997; Boztuğ vd., 2006; Kaygusuz ve Şen, 2011; Kaygusuz ve Aydınçakır, 2009, 2011; Aydınçakır ve Şen, 2013; Aydın, 2014; Yücel vd., 2014; Aydınçakır, 2016; Sipahi vd., 2018, 2019, 2020a,b; Karslı vd., 2017, 2018). Buna karşılık güney zonda ise çoğunlukla alkali potasik kayaçlar yayılım gösterir (Bektaş ve Gedik, 1988; Eyüboğlu, 2010; Gülmez ve Genç, 2015; Şen vd. 2019). Bununla birlikte, bölgede Paleozoyik yaşlı ve gabrodan granite kadar değişen irili ufaklı birçok intrüzif kayaçlar da gözlenmektedir (Çoğulu, 1975; Topuz vd., 2010; Dokuz, 2011; Kaygusuz vd., 2012, 2016; Ustaömer vd., 2013; Karslı vd., 2016; Kaygusuz, 2020; Şekil 1; Çizelge 1). İnceleme alanının yer aldığı bölgede temel birimleri Karbonifer metamorfitler (Pulur Masifi, Karadağ ve Kurtoğlu Metamorfitleri: Topuz vd., 2004, 2007; Dokuz ve Tanyolu, 2006; Dokuz vd., 2006; Ustaömer ve Robertson, 2010) ve onları keserek yerleşen Karbonifer plütonlar (Çoğulu, 1975; Topuz vd., 2010; Dokuz, 2011; Ustaömer vd., 2013; Kaygusuz vd., 2016; Karslı vd., 2016) oluşturmaktadır.

Paleozoyik temel birimler, Alt-Orta Jura volkanik ve volkanoklastik kayaçlardan oluşan ve Liyasik transgresyon (200-190 My) sonucu meydana gelen Şenköy Formasyonu tarafından uyumsuz olarak örtülmektedir (Kandemir ve Yılmaz, 2009). $\mathrm{Bu}$ birim birçok araştırmacı tarafından rift ile ilişkili subalkalen karakterli volkanosedimanter istif olarak nitelendirilmiştir (ör., Ağar, 1977; Dokuz ve Tanyolu, 2006; 
Şen, 2007; Kandemir ve Yılmaz, 2009). Ancak son çalışmalar, Orta Triyas'tan Erken Jura'ya kadar değişen yaş aralıklarında, özellikle yastık debili bazaltların derinlik eşleniklerinin varlığını işaret etmektedir (Karslı vd., 2014; Dokuz vd., 2017; Aydınçakır vd., 2020). Volkano-sedimanter istif üzerine Geç Jura-Erken Kretase sığ platform karbonatları uyumlu olarak gelmekte olup genellikle gri-bej renkli, kalın, yer yer masif katmanlı, sığ denizel bir istif özelliği sunmaktadır (Pelin, 1977).

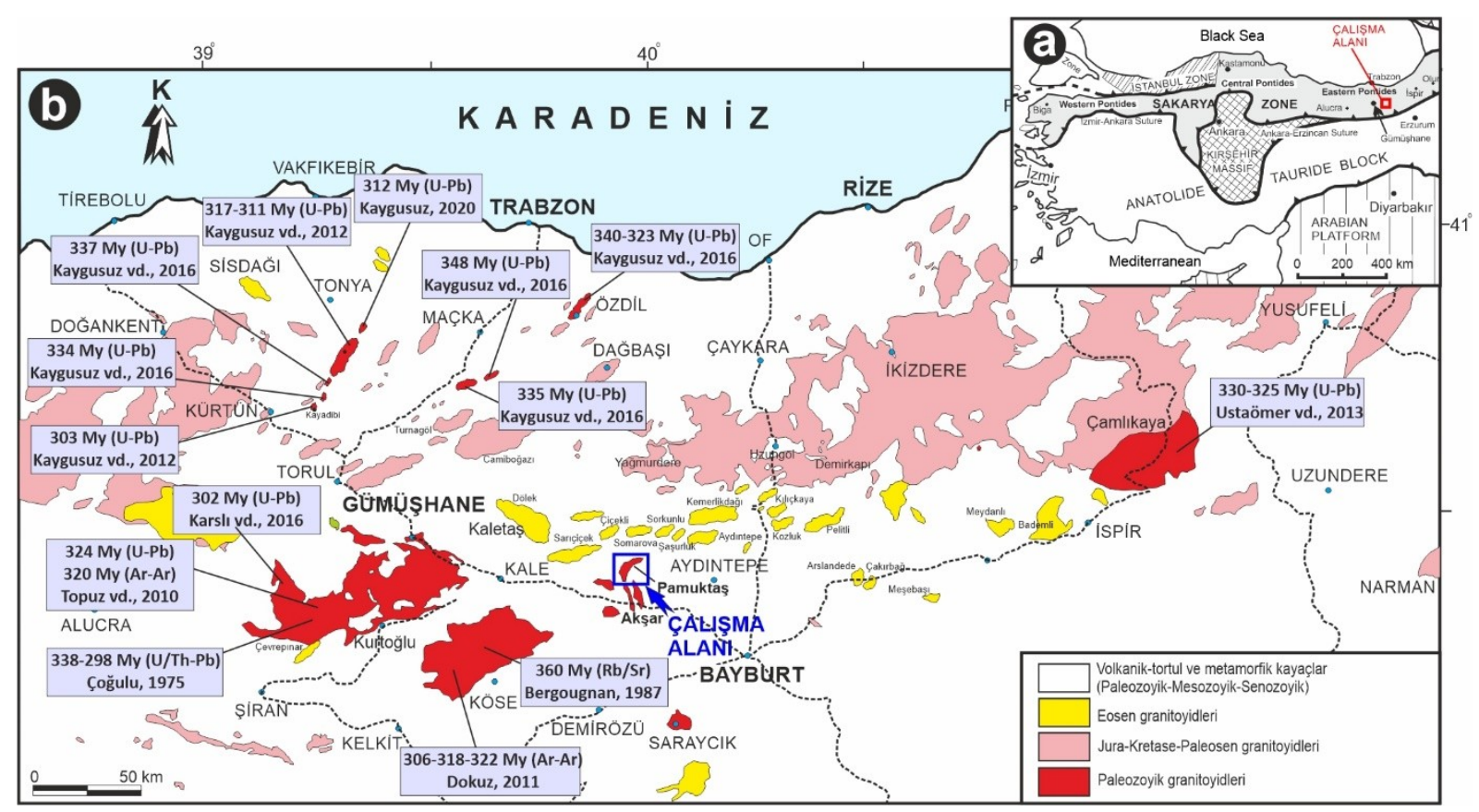

Şekil 1. (a) Türkiye'nin ana tektonik birlikleri (Okay ve Tüysüz, 1999'dan değiştirilmiştir). (b) Doğu Pontid Orojenik Kuşağı'ndaki ana plütonik kayaçların dağılımı (Güven, 1993'ten değiştirilmiştir) ve Paleozoyik plütonlardan elde edilen yaş verileri.

Figure 1. (a) Map of the main tectonic units of Turkey (modified after Okay and Tüysüz, 1999). (b) Distribution of main plutonic rocks in the Eastern Pontide Orogenic Belt (modified after Güven, 1993) and age data from Paleozoic plutons.

Geç Kretase dönemde farklılıklar sergileyen Doğu Pontidler'de, toleyitikten kalkalkalene kadar geniş bir aralıkta mostra veren volkanik kayaçlar, yine Alt Kretase granitleri tarafından kesilmektedir (Okay ve Şahintürk, 1997; Yılmaz vd., 1997; Kaygusuz vd., 2013; Sipahi vd., 2018; Kaygusuz vd., 2021). Geç Kretase, taban kesimlerinde türbiditik istif, üst kesimlerinde volkanik ağırlıklı kayaçlarla temsil edilirken, tüm bu birimler üzerine taban konglomerası ile uyumsuz olarak gelen Eosen üst kesimlere doğru volkanik tüf, Nummulites'li kireçtaşı ve volkanitler ile temsil edilmektedir (ör., Saydam Eker vd., 2016). Kuvaterner alüvyon ve yamaç molozları çalışma alanının en genç birimini oluşturur. 


\section{ÖRNEKLEME VE ANALITIK YÖNTEM}

Pamuktaş (Bayburt) civarında yüzeyleme veren granitik kayaçların mineralojikpetrografik, jeokimyasal ve petrolojik özelliklerini ortaya koymak amacıyla alınan kayaç örnekleri materyal olarak kullanıımıştır. Çalışmanın amacına uygun ve sistematik olarak yaklaşık 20 adet örnek toplanmış, örnek alım noktalarının pusula ve el tipi GPS yardımıyla haritaya işlenmiş ve alanın 1/25.000 ölçekli jeoloji haritası oluşturulmuştur. Seçilen taze kayaçlardan PetroThin (MA381450) marka cihazda petrografik ince kesitler yapılmış ve uygun görülenlerden jeokimyasal analiz amaçlı örnek seçimi gerçekleştirilmiştir.

Çizelge 1. Doğu Pontidler'de yüzeylenen Karbonifer plütonların dağılımı (Kaygusuz, 2020'den değiştirilmiş̧ir).

Table 1. Distribution of Carboniferous plutons in Eastern Pontides (modified after Kaygusuz, 2020).

\begin{tabular}{|c|c|c|c|}
\hline Plüton adı (lokasyonu) & Yaş (My) & Yöntem & Referans \\
\hline Köse (Gümüşhane) & $322.2 \pm 3.8$ & \multirow{3}{*}{ Ar-Ar } & \multirow{3}{*}{ Dokuz, 2011} \\
\hline Köse (Gümüşhane) & $306.6 \pm 4.2$ & & \\
\hline Köse (Gümüşhane) & $318 \pm 2.4$ & & \\
\hline Gümüşhane (Gümüşhane) & 298 & \multirow{3}{*}{$\mathrm{U} /(\mathrm{Th}-\mathrm{Pb})$} & \multirow{3}{*}{ Çoğulu, 1975} \\
\hline Gümüşhane (Gümüşhane) & 304 & & \\
\hline Gümüşhane (Gümüşhane) & 338 & & \\
\hline Gümüşhane (Gümüşhane) & $309.2 \pm 5.3$ & Ar-Ar & \multirow{4}{*}{ Topuz vd., 2010} \\
\hline Gümüşhane (Gümüşhane) & $316.8 \pm 2.9$ & Ar-Ar & \\
\hline Gümüşhane (Gümüşhane) & $319 \pm 5$ & $\mathrm{U}-\mathrm{Pb}$ & \\
\hline Gümüşhane (Gümüşhane) & $329 \pm 6$ & $\mathrm{U}-\mathrm{Pb}$ & \\
\hline Köse (Gümüşhane) & 360 & $\mathrm{Rb} / \mathrm{Sr}$ & Bergougnan, 1987 \\
\hline Çamlık (Gümüşhane) & $302.01 \pm 0.68$ & $\mathrm{U}-\mathrm{Pb}$ & Karslı vd., 2016 \\
\hline Alazlı (Tonya-Trabzon) & $312.1 \pm 2.1$ & $\mathrm{U}-\mathrm{Pb}$ & Kaygusuz, 2020 \\
\hline Derinoba (Tonya-Trabzon) & $317.2 \pm 3.5$ & \multirow{3}{*}{$\mathrm{U}-\mathrm{Pb}$} & \multirow{3}{*}{ Kaygusuz vd., 2012} \\
\hline Derinoba (Tonya-Trabzon) & $311.1 \pm 2.0$ & & \\
\hline Kayadibi (Kürtün-Gümüşhane) & $303.8 \pm 1.5$ & & \\
\hline Özdil (Yomra-Trabzon) & $340.7 \pm 1.8$ & \multirow{6}{*}{$\mathrm{U}-\mathrm{Pb}$} & \multirow{6}{*}{ Kaygusuz vd., 2016} \\
\hline Özdil (Yomra-Trabzon) & $323.1 \pm 1.5$ & & \\
\hline Seslikaya (Maçka-Trabzon) & $335.4 \pm 1.4$ & & \\
\hline Soğuksu (Maçka-Trabzon) & $348.4 \pm 1.6$ & & \\
\hline Şahmetlik (Tonya-Trabzon) & $334.5 \pm 1.4$ & & \\
\hline Kızılağaç (Tonya-Trabzon) & $337.2 \pm 0.69$ & & \\
\hline Çamlıkaya (Yusufeli-Artvin) & $330 \pm 4.0$ & \multirow{3}{*}{$\mathrm{U}-\mathrm{Pb}$} & \multirow{3}{*}{ Ustaömer vd., 2013} \\
\hline Demirkent (Yusufeli-Artvin) & $325 \pm 3.0$ & & \\
\hline Narlık (Yusufeli-Artvin) & $330 \pm 19$ & & \\
\hline
\end{tabular}


Birimi temsilen seçilen 9 örneğin ana, iz ve nadir toprak element analizleri yaptırılmış, bunlardan yararlanılarak granitik kayaçların petrokimyasal ve petrolojik özellikleri genel olarak ortaya konmuştur. Tüm kayaç jeokimya analizleri ACME Analiz Laboratuvarı (Vancouver, Kanada)'nda gerçekleştirilmiştir. Ana ve iz elementler İndüktif Eşleşmiş Plazma-Emisyon Spektrometresi (ICP-ES: Inductively Coupled Plasma-Emission Spectrometry), iz ve nadir toprak element analizleri ise İndüktif Eşleşmiş Plazma-Kütle Spektrometresi (ICP-MS: Inductively Coupled Plasma-Mass Spectrometry) yöntemiyle yapılmıştır. Öğütülen toz örneklerden $0.2 \mathrm{gr}$ alınarak $1.5 \mathrm{gr}$ $\mathrm{LiBO}_{2}$ ile karıştırılmış ve \%5 $\mathrm{HNO}_{3}$ içeren bir sıvı içinde çözündürülmüştür. Ana elementler \% ağırlık, iz elementler ise ppm olarak ölçülmüştür. Nadir toprak elementler ise, toz örneklerden $0.25 \mathrm{gr}$ alınarak farklı asitler içerisinde çözündürülmüş ve analiz sonuçları ppm olarak tespit edilmiştir. Analiz yapılan cihaza referans materyal olarak STD GS311-1, STD GS910-4, STD SO-19, STD SO-19, STD DS11 ve STD OREAS262 standartları girilmiştir. Ana element analizlerinde, toplam demir $\mathrm{Fe}_{2} \mathrm{O}_{3}{ }^{\top}$ cinsinden ölçülmüştür. Ateşte kayıp miktarını belirlemek için öncelikle örneğin nemi uzaklaştırımıştır. Bunun için önceden belirlenen miktarda örnek alınarak $105^{\circ} \mathrm{C}$ 'de 24 saat fırında kurutulmuş ve tartılarak ağırlığı belirlenmiştir. Karbondioksit ve sülfür gazı ölçümleri için \%2'lik C ve \%1'lik S standartları hazırlanmış ve analize hazır hale getirilmiştir. Örnekler daha sonra yaklaşık 1 saat $1000^{\circ} C^{\prime}$ lik sıcaklığa maruz bırakılmıştır. Isıtmadan önce ve sonraki ağırlıklar kontrol edilerek su, karbondioksit ve sülfür kayıpları belirlenmiş ve iki tartı arasındaki farkın yüzdesi alınarak örneklerin ateşte kaybı (AK) tespit edilmiştir. Burada sunulan çeşitli jeokimyasal sınıflandırmalar ve jeotektonik diyagramlar, Geochemical Data Toolkit (GCDkit) sürüm 6.0_2019 yazılımı (Janoušek vd., 2006, http://www.gcdkit.org/) kullanılarak çizilmiştir.

\section{BULGULAR}

\section{Saha İlişkileri ve Petrografi}

Pamuktaş Köyü (Bayburt, KD Türkiye) ve yakın civarını içerisine alan inceleme alanında granitik kayaçlar yaklaşık $5 \mathrm{~km}^{2}$ 'lik bir alanda yüzeylemektedir. Karbonifer Pamuktaş Plütonu çalışma alanında Jura öncesi temeli temsil etmekte olup Erken- 
Orta Jura volkanoklastik ve volkanik kayaçlar ile Üst Jura-Alt Kretase kireçtaşları tarafından uyumsuz olarak örtülmektedir (Şekil 2).

Pamuktaş Plütonu, Keskin vd. (1989) tarafından Akşar Beldesi dolaylarında yayılım gösteren granitik kayaçlar için tanımladığı "Akşar Graniti” içerisinde yer almaktadır.

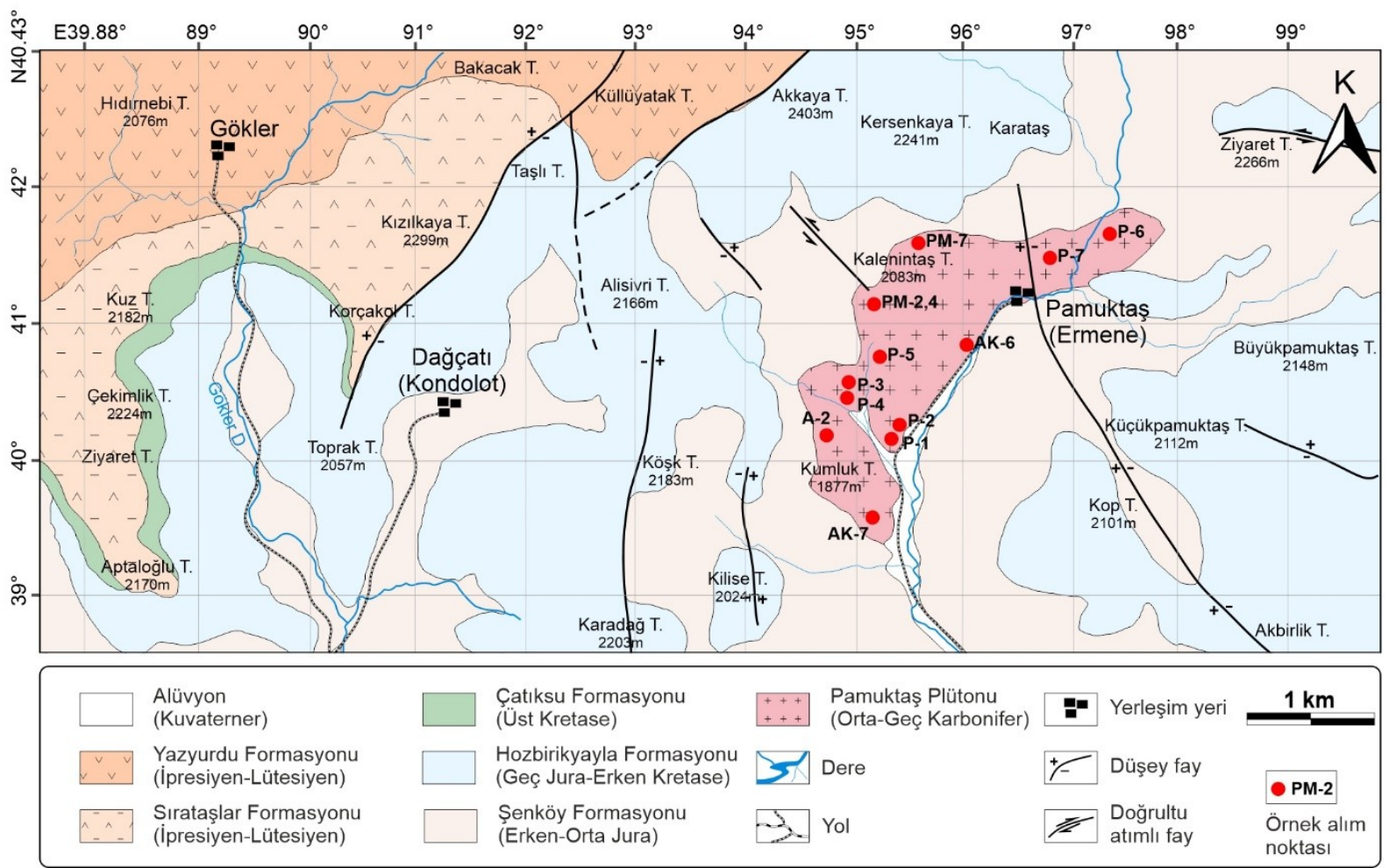

Şekil 2. Çalışma alanı ve yakın çevresinin jeoloji haritası.

Figure 2. Geological map of the study area.

Ancak bu çalışma kapsamında, pembe renkli iri kristalli görünümü ile dikkat çeken granitik kayaçlar için, tip yerlerden biri olan Pamuktaş Köyü'ne atfen ilk kez "Pamuktaş Plütonu" olarak adlandırılmıştır (Şekil 3a, b). Genellikle Pamuktaş Köyü ve yakın civarında, Kumluk Tepe ve Kalenintaş Tepe dolaylarında yüzeyleme vermektedir. İri kristalli ve pembe rengi ile arazide kolayca tanınmaktadır. Birim tek bileşimde olmayıp, pembe renkli, orta-iri kristalli granit/mikrogranit (Şekil 3c), granodiyorit / mikrogranodiyorit (Şekil 3d) ve aplit (Şekil 3e) türü kayaçlardan meydana gelmektedir; yer yer ileri derecede arenalaşmıştır (Şekil 3f). Çatlaklar çoğunlukla ikincil karbonat, kil mineralleri ve silis dolguludur. Birimde yapılmış bir yaş çalışması bulunmayıp, Gümüşhane yöresinde benzer litolojiye sahip Gümüşhane Graniti'nden dolayı yaşı Orta-Geç Karbonifer olarak alınmıştır. 

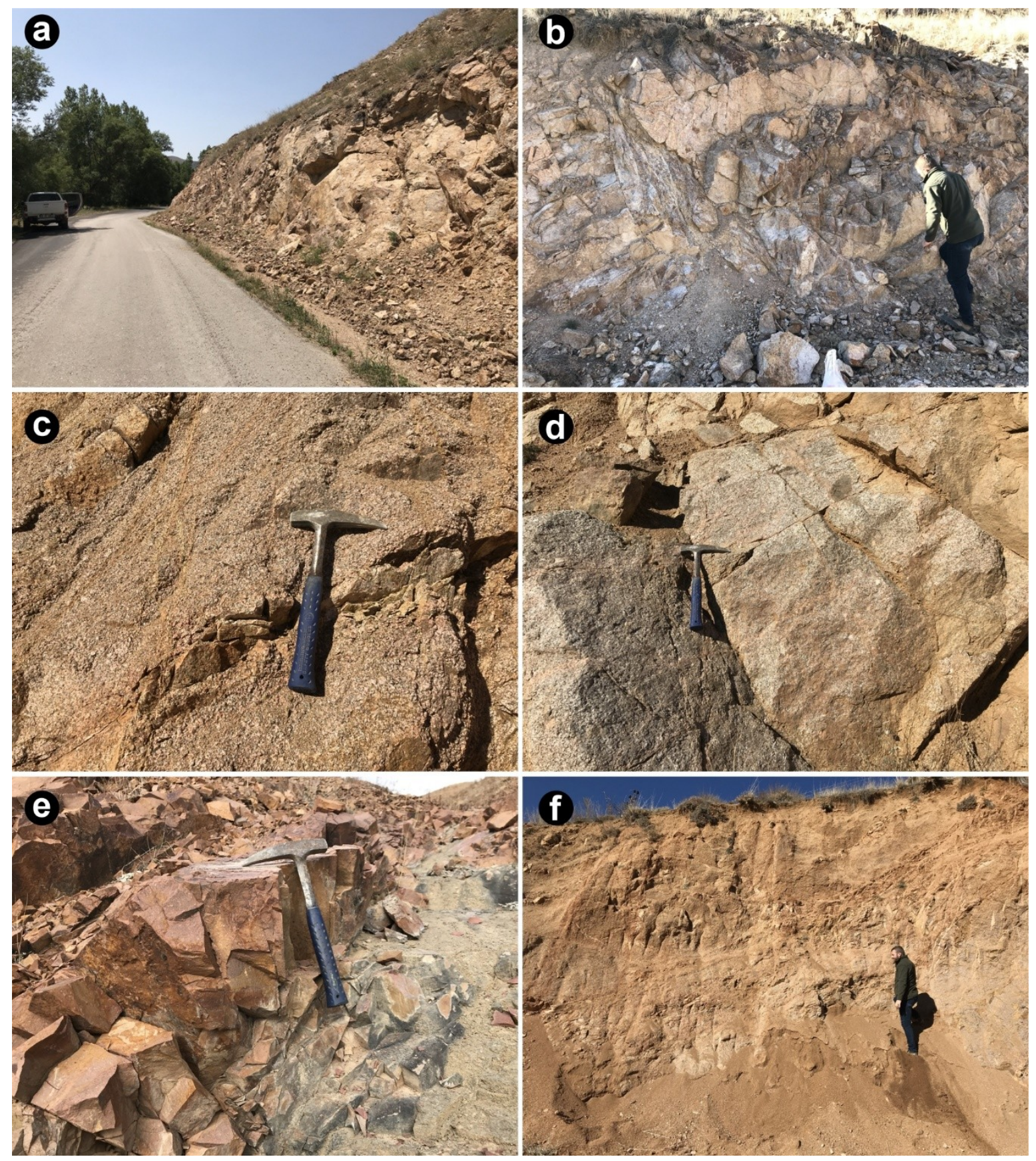

Şekil 3. Pamuktaş Plütonu granitik kayaçlarının saha fotoğrafları.

Figure 3. Field photographs of granitic rocks from the Pamuktaş Pluton.

Granitik kayaçların farklı türlerinden meydana gelen Pamuktaş Plütonu başlıca granit/aplit (mikrogranit), granodiyorit ve kuvarslı mikrodiyorit olmak üzere üç ana grupta incelenmiştir.

Birim içerisinde en yaygın kayaç grubunu oluşturan granit el örneklerinde tipik pembe rengi ve orta-iri kristalli mineralojik bileşimi ile dikkat çekmekte, boyutları $0.5-2 \mathrm{~cm}$ arasında değişen iri feldispat (pembe renkli ortoklas) kristalleri yanında bol miktarda 
kuvars, plajiyoklas ve opak mineralleri içermektedir. Ferromagnezyen minerallerden ise biyotit ve hornblend yer almaktadır. Bazı örneklerde opak mineraller, ikincil muskovit ve klorit mineralleri ile alterasyon ürünü olan serizitleşme, killeşme, karbonatlaşma ve silisleşmeler de izlenebilmektedir. Birimin kenar zonları boyunca görülen mikrogranitler (aplitler) ise daha ince taneli olarak gelişmiştir. Ayrışma yüzeyleri killeşmeden dolayı daha açık renklidir.

Açık renkli mineraller bolluk sırasına göre kuvars, ortoklas ve plajiyoklasdan oluşurken, koyu renkli mineraller genellikle biyotitlerden meydana gelmektedir (Şekil 4a,b). Kuvars, yaklaşık \%30-35 civarında, öz şekilsiz, yer yer iri kristaller halindedir.

Büyük oranda çatlaklı ve kırıklı bir şekilde ve deforme olmuş halde gözlenmektedir (Şekil 4c,d). K-Feldispat (ortoklas), örneklerde yaklaşık \%25-30 civarında bulunmakta ve yarı özşekilli ve özşekilsiz olarak gözlenmektedir. Bazı kristallerde küçük plajiyoklas ve amfibol mineral inklüzyonları görülmekte olup poikilitik dokuyu oluşturur. Plajiyoklas, yaklaşık \%20-25 arasında bulunmakta ve çoğunlukla yarı öz şekilli olarak gözlenmektedir. Sönme açıları $16-20^{\circ}$ arasında değişen plajiyoklasların cinsleri oligoklas $\left(\mathrm{An}_{23-25}\right)$ olarak bulunmuştur. Kristallerin büyük bir çoğunluğunda serizitleşmeler görülür. Sınırları boyunca yer yer killeşmeler de izlenebilmektedir. Albit ikizlenmesi ve bazıları da zonlu yapı göstermektedir (Şekil 4e). Biyotit, kesitte \%3-4 civarında bulunmakta ve kahverengi rengi ile ayırt edilmektedir (Şekil 4b).

Kısmen özşekilli ve çoğunlukla yarı özşekilli gelişmiştir. Opak mineraller, kayaç içerisinde küçük kristaller halinde, çok az miktarda (\%1 civarında) ve dağınık şekilde gözlenmektedir. Özellikle amfibol ve biyotit gibi mafik minerallerin bulunduğu bölgelerde yoğunlaşmışlardır. İkincil mineraller serizit, kil ve kalsit olarak ortaya çıkar. 

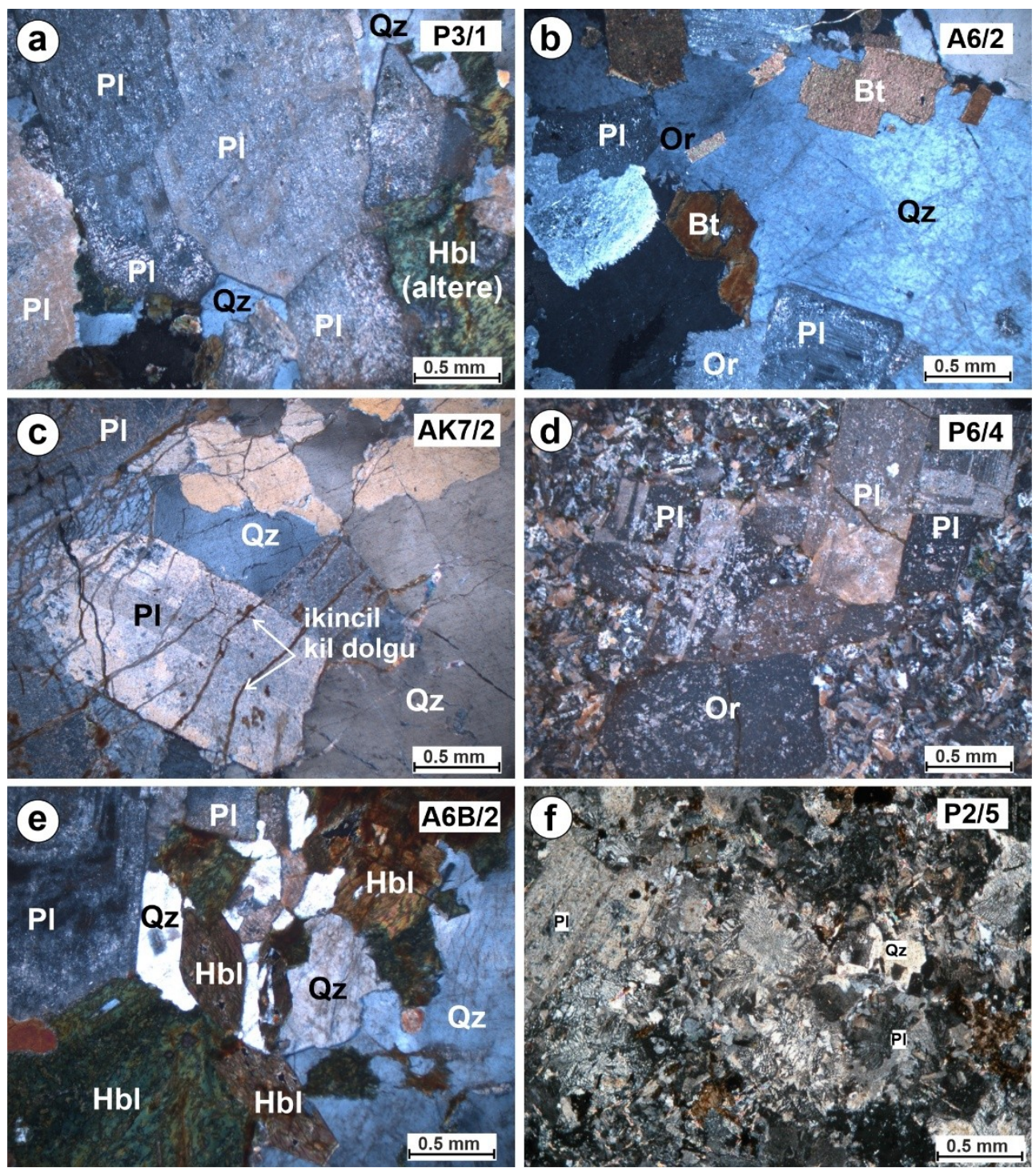

Şekil 4. Pamuktaş Plütonu örneklerinin mikrofotoğrafları. (a)-(c) Granit, (d) Granit porfir, (e) Granodiyorit ve (f) Kuvarslı mikrodiyorit. PI: Plajyoklas, Qz: Kuvars, Or: Ortoklas, Bt: Biyotit, $\mathrm{Hbl}$ : Hornblend (görüntüler çapraz nikolde alınmıştır).

Figure 4. Photomicrographs from the Pamuktaş Pluton. (a)-(c) Granite, (d) Granite porphyry, (e) Granodiorite and (f) Quartz microdiorite. Pl: Plagioclase, Qz: Quartz, Or: Orthoclase, Bt: Biotite, Hbl: Hornblend (the images was taken in crossed nicols).

Pamuktaş Plütonu içerisinde yayılımı az olan granodiyorit genellikle plajiyoklas içeriğine bağlı olarak rengi açık gri ve yer yer pembemsi olup nispeten taze görünümlüdür. Açık renkli mineraller bolluk sırasına göre plajiyoklas, kuvars ve ortoklas, koyu renkli mineraller genellikle hornblend türündedir (Şekil 4e). Plajiyoklas, genellikle iri kristalli ve yarı özşekilli olarak gelişmiş ve çoğunlukla ayrışmış durumdadır. Kayaçlarda yaklaşık \%40-42 civarında bulunmaktadır. Sönme açılarına $\left(16-20^{\circ}\right)$ göre cinsleri andezin $\left(A n_{34-40}\right)$ olarak belirlenmiştir. Büyük plajiyoklas kristalleri üzerinde yer yer hornblend ve mafik mineral kapanımları görülmektedir. 
Kuvars, genellikle öz şekilsiz fenokristaller halinde, kırıklı ve çatlaklı bir yapıda olup yaklaşık \%25 civarındadır. Ortoklas, yaklaşık \%20 oranında görülmekte ve özşekilsiz kristaller halindedir. Yer yer ayrışarak serizitleşmişlerdir. Hornblend, yarı öz şekilli, yer yer ise özşekilli gelişmiş kristaller halindedir. Bazı kesitlerde iki yönlü dilinimleri belirgin olarak izlenebilmektedir (Şekil 4e). Bazı hornblendler ayrışarak klorite dönüşmüştür. Örneklerde \%4-5 civarında bulunmaktadır. Opak mineraller, irili ufaklı öz şekilsiz kristaller halinde ve dağınık halde bulunur. Çoğunlukla mafik mineraller ile bir arada gözlenirler. İkincil mineraller, serizit ve klorit olup feldispat ve hornblend minerallerinin ayrışma ürünleri olarak ortaya çıkmaktadır.

Plütonda yayılımı en az olan kuvarslı mikrodiyoritler sahada tipik ince doku göstermeleriyle granitlerden ayırt edilmektedir. Kuvars, genellikle ince kristalli ve yer yer orta büyüklükte taneler halinde bulunur. Çoğunlukla yarı özşekilli ve özşekilsizdir. Plajiyoklas diğer minerallere nazaran daha iri gelişmiş olan fenokristaller halindedir. Ortoklas öz şekilsiz ve çoğunlukla mikro kristaller halinde bulunmaktadır. Ayrışmadan dolayı kil ve serizit mineralleri gelişmiştir. Ortoklas ve kuvars minerallerinin yan yana ışınsal, radyal ve sferik olarak büyümesi sonucu reaksiyon dokuları gelişmiştir (Şekil 4f).

\section{Tüm Kayaç Jeokimyası}

Pamuktaş Plütonu'nu oluşturan granitik kayaçların jeokimyasal özelliklerini, magma tipini ve kökenini saptamak amacıyla seçilen örneklerden ana (\%), iz (ppm) ve nadir toprak element (ppm) analizleri gerçekleştirilmiş ve sonuçlar Çizelge 2'de verilmiştir.

Örneklerin $\mathrm{SiO}_{2}$ ve $\mathrm{Al}_{2} \mathrm{O}_{3}$ içerikleri genel olarak yüksek olup sırasıyla \%65.62-75.09 ve \%12.80-14.71 arasında değişmektedir. Buna karşılık, genellikle düşük $\mathrm{Fe}_{2} \mathrm{O}_{3}{ }^{\top}$ (\%2.89-4.78), $\mathrm{MgO}(\% 0.07-1.10)$ ve $\mathrm{TiO}_{2}$ (\%0.13-0.48) içeriklerine sahiptir. Kayaçların mineralojik bileşimleri ile uyumlu olarak nispeten yüksek $\mathrm{K}_{2} \mathrm{O}$ (\%3.474.69) ve $\mathrm{Na}_{2} \mathrm{O}$ (\%2.77-4.37) içerirler. $\mathrm{Na}_{2} \mathrm{O}+\mathrm{K}_{2} \mathrm{O}$ değerleri \%7.14-8.34 arasında değişmekle birlikle, Middlemost (1994)'un Toplam Alkali Sınıflama (TAS) diyagramına göre, çoğunlukla granit (7 örnek), az oranda granodiyorit (2 örnek) bileşimine karşılık gelmektedir (Şekil 5a). Düşük $\mathrm{MgO}$ ve $\mathrm{Fe}_{2} \mathrm{O}_{3}{ }^{\top}$ ile çok düşük $\mathrm{Mg \#}$ (molar $\mathrm{MgO} /\left(\mathrm{MgO}+\mathrm{FeO}_{\text {tot }}\right.$ ) değerleri (5-31) içerikleri granitik kayaçların kalk-alkalen 
Çizelge 2. Pamuktaş Plütonu granitlerinin ana (\%), iz (ppm) ve nadir toprak element (ppm) analiz sonuçları.

Table 2. Results of major oxide (wt\%), trace (ppm) and rare earth (ppm) element analyses of granites of the Pamuktaş Pluton.

\begin{tabular}{|c|c|c|c|c|c|c|c|c|c|}
\hline Örnek No & AK6 & AK7 & P1 & P2 & P3 & P4 & P5 & P6 & P7 \\
\hline $\mathrm{SiO}_{2}$ & 66.50 & 66.06 & 74.17 & 75.09 & 70.72 & 69.49 & 65.62 & 70.14 & 71.23 \\
\hline $\mathrm{Al}_{2} \mathrm{O}_{3}$ & 14.12 & 14.71 & 12.87 & 12.80 & 14.21 & 14.67 & 13.97 & 14.04 & 13.77 \\
\hline $\mathrm{Fe}_{2} \mathrm{O}_{3}{ }^{\top}$ & 4.39 & 4.62 & 2.92 & 2.89 & 4.71 & 4.45 & 4.78 & 4.67 & 3.59 \\
\hline $\mathrm{MgO}$ & 0.36 & 0.85 & 0.12 & 0.07 & 0.47 & 0.21 & 1.10 & 0.44 & 0.43 \\
\hline $\mathrm{CaO}$ & 0.56 & 1.58 & 0.60 & 0.25 & 0.46 & 0.84 & 1.64 & 0.92 & 0.78 \\
\hline $\mathrm{Na}_{2} \mathrm{O}$ & 4.37 & 2.77 & 2.82 & 3.25 & 4.00 & 3.80 & 2.84 & 3.81 & 3.65 \\
\hline $\mathrm{K}_{2} \mathrm{O}$ & 3.97 & 4.37 & 4.38 & 4.14 & 3.47 & 3.94 & 4.69 & 4.26 & 4.17 \\
\hline $\mathrm{TiO}_{2}$ & 0.28 & 0.48 & 0.14 & 0.13 & 0.27 & 0.35 & 0.44 & 0.23 & 0.24 \\
\hline $\mathrm{P}_{2} \mathrm{O}_{5}$ & 0.07 & 0.11 & 0.03 & 0.03 & 0.07 & 0.09 & 0.11 & 0.06 & 0.07 \\
\hline $\mathrm{MnO}$ & 0.07 & 0.09 & 0.06 & 0.05 & 0.06 & 0.05 & 0.08 & 0.10 & 0.06 \\
\hline $\mathrm{Cr}_{2} \mathrm{O}_{3}$ & 0.008 & 0.005 & 0.004 & 0.003 & 0.007 & 0.006 & 0.005 & 0.01 & 0.006 \\
\hline A.K. & 3.10 & 4.20 & 1.80 & 1.10 & 1.30 & 1.90 & 4.40 & 1.00 & 1.80 \\
\hline Toplam & 97.92 & 99.86 & 99.93 & 99.93 & 99.87 & 99.88 & 99.85 & 99.81 & 99.86 \\
\hline $\mathrm{Ba}$ & 975 & 672 & 913 & 934 & 1246 & 1170 & 1195 & 1218 & 1046 \\
\hline Sc & 10 & 8 & 5 & 5 & 7 & 9 & 9 & 8 & 6 \\
\hline $\mathrm{Be}$ & 2 & 3 & 3 & 3 & 4 & 4 & $<1$ & 3 & 3 \\
\hline Co & 3.3 & 5.4 & 2.3 & 1.9 & 3.8 & 4.2 & 6.2 & 3.7 & 3.2 \\
\hline $\mathrm{Ni}$ & 12.9 & 7.4 & 7 & 7.3 & 9.7 & 10.7 & 9.4 & 12.9 & 8.9 \\
\hline Cs & 1.1 & 3.1 & 6.1 & 4.4 & 1.4 & 1.8 & 2.8 & 1.1 & 0.9 \\
\hline $\mathrm{Ga}$ & 18.8 & 17.6 & 15.3 & 15.2 & 17.3 & 18.7 & 16.5 & 18.4 & 17.5 \\
\hline $\mathrm{Hf}$ & 6.6 & 5.2 & 3.6 & 3.6 & 6 & 6.8 & 4.7 & 6.6 & 4.9 \\
\hline $\mathrm{Nb}$ & 12.6 & 12.1 & 9.1 & 9.7 & 10.3 & 11.4 & 11.3 & 12.5 & 10.5 \\
\hline $\mathrm{Rb}$ & 103.2 & 113.4 & 122.4 & 119.2 & 98.2 & 114.6 & 133.9 & 118 & 121.5 \\
\hline Sn & 4 & 5 & 3 & 3 & 4 & 4 & 5 & 5 & 4 \\
\hline $\mathrm{Sr}$ & 131.6 & 200 & 83 & 107 & 119.5 & 139.6 & 229.8 & 143.9 & 141.1 \\
\hline $\mathrm{Ta}$ & 0.9 & 0.9 & 0.5 & 0.7 & 0.6 & 0.6 & 0.8 & 0.8 & 0.8 \\
\hline Th & 14.4 & 15.1 & 17.2 & 13.5 & 13.8 & 13.8 & 11.9 & 16.7 & 14.5 \\
\hline$U$ & 4.3 & 3.7 & 1.5 & 1.9 & 2.3 & 2.5 & 2.8 & 3.5 & 3.4 \\
\hline V & 17 & 41 & 8 & 10 & 14 & 22 & 37 & 14 & 16 \\
\hline W & 1 & 0.9 & 1.2 & 0.9 & 1.4 & 1.7 & 0.9 & 2.7 & 1.5 \\
\hline $\mathrm{Zr}$ & 241.8 & 182 & 111.1 & 104.9 & 219.5 & 261.9 & 168.1 & 240.9 & 166.7 \\
\hline $\mathrm{Y}$ & 29.9 & 25 & 22.8 & 29 & 26.2 & 27.6 & 22.6 & 31.6 & 23.7 \\
\hline La & 45.7 & 38 & 34.8 & 36.5 & 42.3 & 43.5 & 34.8 & 50.5 & 39.9 \\
\hline $\mathrm{Ce}$ & 87.8 & 71.7 & 63.3 & 70 & 79 & 82.8 & 66.9 & 95.9 & 75.8 \\
\hline $\mathrm{Pr}$ & 10.18 & 8.59 & 7.31 & 8.02 & 8.77 & 9.44 & 7.94 & 10.9 & 8.62 \\
\hline $\mathrm{Nd}$ & 36.5 & 30.9 & 26.2 & 29.1 & 31.9 & 35.4 & 29.3 & 39.9 & 31 \\
\hline Sm & 7.04 & 6.01 & 4.74 & 5.85 & 5.5 & 6.54 & 5.88 & 7.23 & 5.73 \\
\hline $\mathrm{Eu}$ & 0.98 & 0.93 & 0.57 & 0.58 & 1.07 & 1.11 & 1.02 & 0.89 & 0.78 \\
\hline $\mathrm{Gd}$ & 6.25 & 5.3 & 4.5 & 5.27 & 5.19 & 5.92 & 5.2 & 6.28 & 5.03 \\
\hline $\mathrm{Tb}$ & 0.95 & 0.79 & 0.7 & 0.83 & 0.78 & 0.86 & 0.76 & 0.94 & 0.75 \\
\hline Dy & 5.59 & 4.41 & 4.09 & 5.17 & 4.75 & 5.25 & 4.48 & 5.39 & 4.29 \\
\hline Ho & 1.1 & 0.83 & 0.83 & 1.05 & 0.98 & 1.01 & 0.84 & 1.1 & 0.85 \\
\hline Er & 3.18 & 2.51 & 2.47 & 3.11 & 2.92 & 2.99 & 2.39 & 3.06 & 2.52 \\
\hline $\mathrm{Tm}$ & 0.45 & 0.36 & 0.35 & 0.45 & 0.42 & 0.44 & 0.35 & 0.44 & 0.35 \\
\hline $\mathrm{Yb}$ & 3.06 & 2.47 & 2.42 & 3.09 & 2.76 & 2.92 & 2.23 & 2.99 & 2.38 \\
\hline Lu & 0.47 & 0.36 & 0.38 & 0.45 & 0.45 & 0.46 & 0.33 & 0.45 & 0.36 \\
\hline Mg\# & 14 & 27 & 8 & 5 & 17 & 9 & 31 & 16 & 19 \\
\hline $\mathrm{Eu} / \mathrm{Eu}^{*}$ & 0.45 & 0.50 & 0.38 & 0.32 & 0.61 & 0.55 & 0.56 & 0.40 & 0.44 \\
\hline
\end{tabular}

$\mathrm{Fe}_{2} \mathrm{O}_{3}{ }^{\prime}: \mathrm{Fe}_{2} \mathrm{O}_{3}$ cinsinden toplam demir. A.K. (Ateşte Kayıp): Toplam uçucu içeriği. Mg\# = molar MgO $/ \mathrm{molar}$ $\left(\mathrm{MgO}+\mathrm{FeO}^{\top}\right)^{*} 100 . \mathrm{Eu}^{\mathrm{E}} \mathrm{Eu}^{*}=\mathrm{Eu}_{N} / \sqrt{ }\left(\mathrm{Sm}_{N} \times \mathrm{Gd} N\right), \mathrm{N}=$ Kondridit değerleri (Boynton, 1984). 
bir afiniteye sahip olduğunu işaret etmekte, Irvine ve Baragar (1971)'ın alkalisubalkali sınıflamasına göre ise kalk-alkalen bölgede yer almaktadır (Şekil 5b). Plütona ait kayaçların, Peccerillo ve Taylor (1976)'ın $\mathrm{SiO}_{2}-\mathrm{K}_{2} \mathrm{O}$ diyagramında (Şekil 5c) genellikle yüksek-K kalk-alkali karakterli olduğu görülmektedir. Örneklerin $\mathrm{Al}_{2} \mathrm{O}_{3}$, $\mathrm{Zr}, \mathrm{Nb}, \mathrm{Ce}, \mathrm{Y}, \mathrm{Ga}$ değerleri Pamuktaş Plütonu kayaçlarının I-tipi bir magmadan itibaren türediğini göstermektedir. İncelenen örneklerin magmaları, A/NK karşı A/CNK diyagramına göre peralümin karakterlidir (Şekil 5d).

Granitlerin $\mathrm{SiO}_{2}$ 'e karşı ana (\%) ve iz (ppm) element değişim diyagramları Şekil 6'da verilmiştir. Nispeten geniş bir aralıkta değişen $\mathrm{SiO}_{2}$ içerikleri nedeniyle belirgin trendler gözlenmekte olup negatif veya pozitif dağılımlar magmadaki kristal fraksiyonlaşmasına işaret etmektedir. $\mathrm{SiO}_{2}$ içeriklerine karşılık $\mathrm{K}_{2} \mathrm{O}$ dışındaki ana oksitlerde belirgin negatif ilişkiler gözlenmektedir.
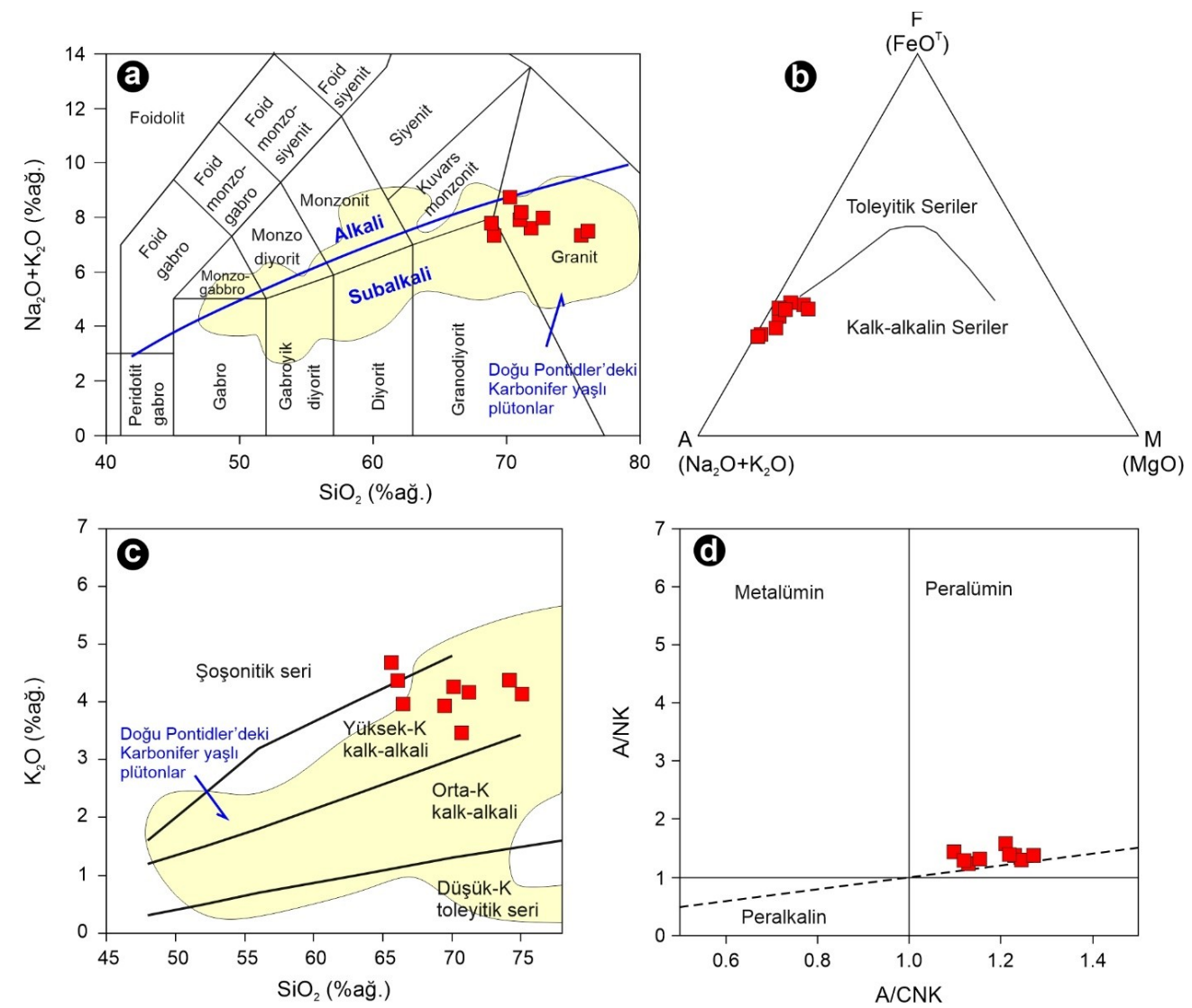

Şekil 5. (a) Toplam Alkali Silis (TAS) sınıflama diyagramı (Middlemost, 1994), (b) AFM $\left(\mathrm{Na}_{2} \mathrm{O}+\mathrm{K}_{2} \mathrm{O}, \mathrm{Fe}_{2} \mathrm{O}_{3}{ }^{\top}, \mathrm{MgO}\right)$ diyagramı (toleyitik-kalk-alkalen ayırım eğrisi Irvine ve Baragar, 1971'e göredir), (c) $\mathrm{K}_{2} \mathrm{O}$ (\%ağ.) $-\mathrm{SiO}_{2}$ (\%ağ.) diyagramı (Peccerillo ve Taylor, 1976) ve (d) Molar A/CNK $\left[\mathrm{Al}_{2} \mathrm{O}_{3} /\left(\mathrm{CaO}+\mathrm{Na}_{2} \mathrm{O}+\mathrm{K}_{2} \mathrm{O}\right)\right]$ 'ya karşı A/NK $\left[\left(\mathrm{Al}_{2} \mathrm{O}_{3}\right) /\left(\mathrm{Na}_{2} \mathrm{O}+\mathrm{K}_{2} \mathrm{O}\right)\right]$ (Shand, 1943).

Figure 5. (a) Total Alkali Silica (TAS) classification diagram (Middlemost, 1994), (b) AFM $\left(\mathrm{Na}_{2} \mathrm{O}+\mathrm{K}_{2} \mathrm{O}, \mathrm{Fe}_{2} \mathrm{O}_{3}{ }^{\top}, \mathrm{MgO}\right)$ diagram (the boundary between tholeiitic and calc-alkaline fields is according to Irvine and Baragar, 1971), (c) $\mathrm{K}_{2} \mathrm{O}$ (wt.\%)-SiO $\mathrm{Si}_{2}$ (wt.\%) diagram (Peccerillo and Taylor, 1976), and (d) Molar A/CNK[Al $\left.\mathrm{O}_{3} /\left(\mathrm{CaO}+\mathrm{Na}_{2} \mathrm{O}+\mathrm{K}_{2} \mathrm{O}\right)\right]$ versus $\mathrm{A} / \mathrm{NK}$ $\left[\left(\mathrm{Al}_{2} \mathrm{O}_{3}\right) /\left(\mathrm{Na}_{2} \mathrm{O}+\mathrm{K}_{2} \mathrm{O}\right)\right]$ (Shand, 1943). 

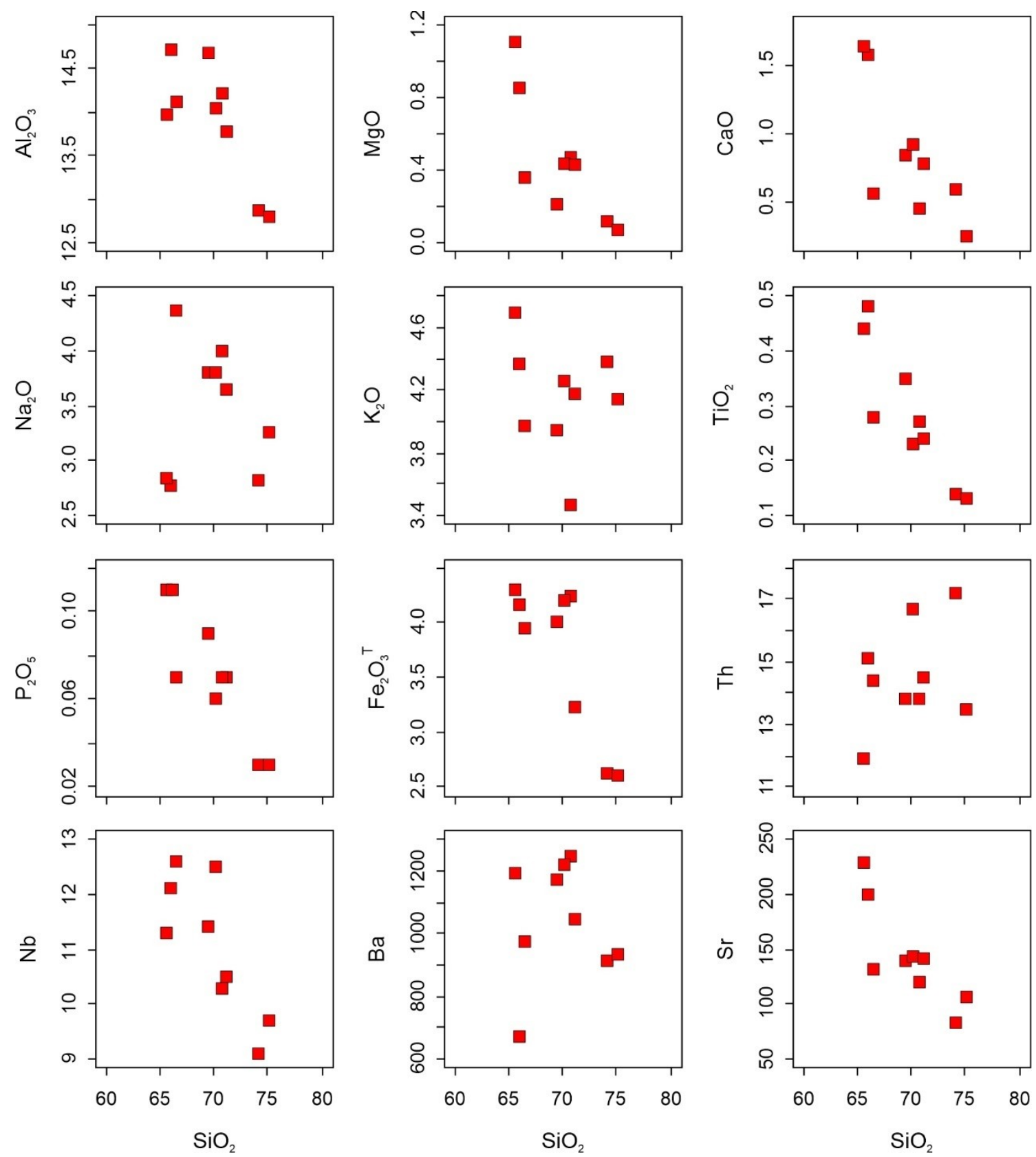

Şekil 6. Granitlerin $\mathrm{SiO}_{2}$ (\%ağ.)'ye karşı ana oksit (\%ağ.) ve iz element (ppm) değişim diyagramları.

Figure 6. $\mathrm{SiO}_{2}$ (wt.\%) versus major oxide (wt.\%) and trace element (ppm) variation diagrams of the granites.

İlksel manto değerlerine oranla tüm örneklerin $\mathrm{Nb}$, Ta, La, P ve Ti değerlerinde belirgin negatif, $\mathrm{K}$ ve $\mathrm{Pb}$ değerlerinde ise belirgin pozitif anomaliler gözlenmektedir (Şekil 7a). Büyük İyon Yarıçaplı Elementler (BiYE; Cs, Rb, Ba, K) ve Ce, Th açısından zenginleşmeler, bazı Yüksek Çekim Alanlı Elementler (YÇAE; Ti), Nb, Ta, $\mathrm{P}$ açısından ise tüketilmeler gözlenmektedir. Dy, Y, Yb ve Lu elementleri paralel bir yönseme izlenirken, Cs elementinde ilksel manto ve kıtasal kabuk bileşimine göre 
zenginleşme daha yüksek oranda gözlenir. Benzer şekilde, Th ve Ce elementleri de pozitif anomali göstermektedir. Kondrite (Boynton, 1984) normalize Nadir Toprak Element (NTE) dağılım diyagramında örnekler genel olarak yukarıya doğru içbükey bir dağılım sunmaktadır (Şekil 7b). Tüm örneklerde NTE bakımından zenginleşme $\left(L a_{N} / Y_{b_{N}}=7.96-11.39\right)$ gözlenmekte iken, ağır nadir toprak elementler, hafif nadir toprak elementlere oranla kendi içlerinde daha az oranda zenginleşmiştir $\left(\mathrm{Gd}_{N} / \mathrm{Lu}_{N}=1.43-1.96 ; \mathrm{La}_{N} / \mathrm{Sm}_{N}=3.72-4.84\right)$. Plajiyoklas ve biyotit gibi minerallerin ayrımlaşmasına işaret eden (ör., McLennan, 1989) negatif Eu anomalisi $\left(\mathrm{Eu}_{\mathrm{N}} / \mathrm{Eu}^{*}=0.32-0.61\right)$ oldukça belirgindir.
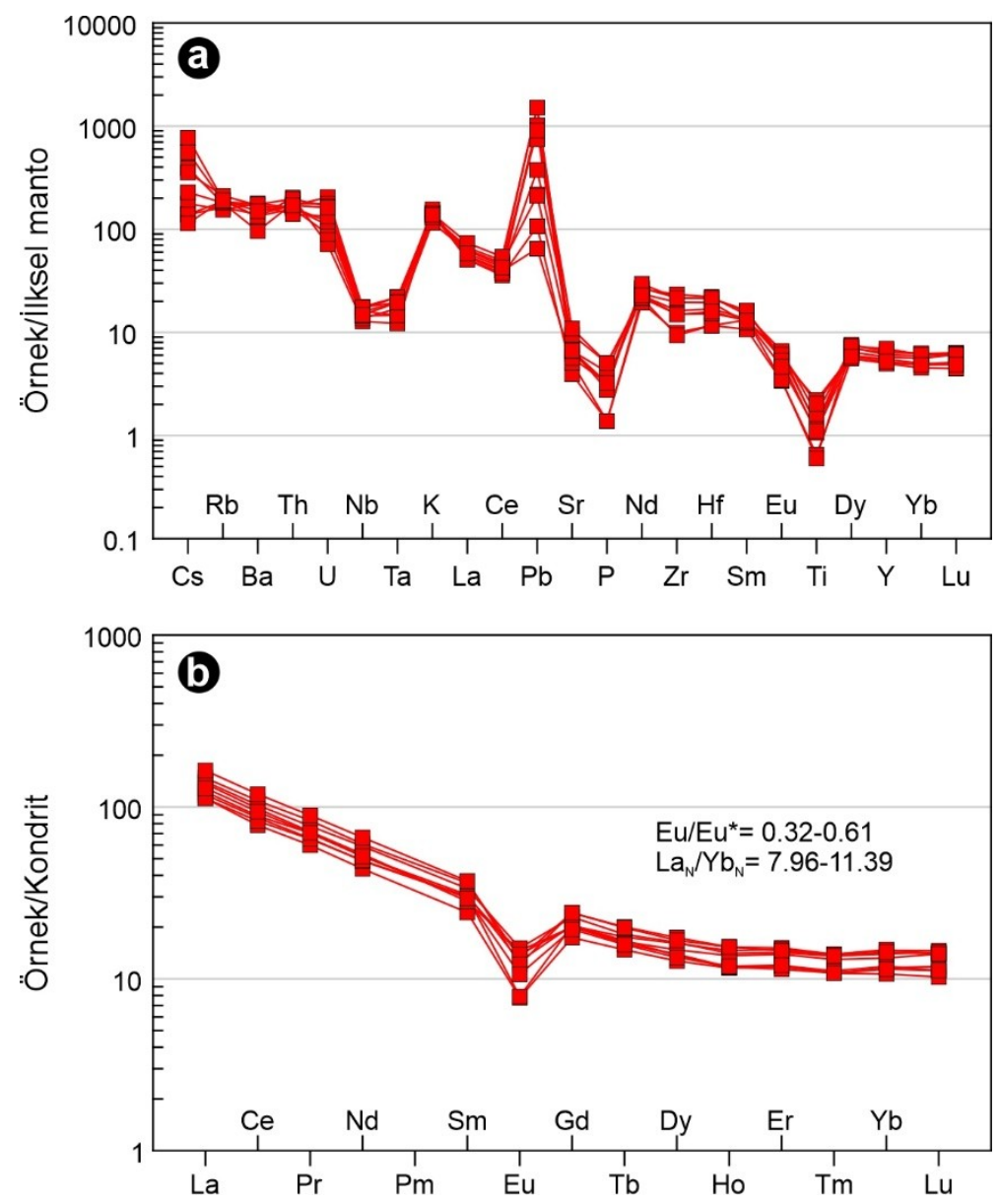

Şekil 7. Örneklerin (a) İlkel manto (Sun ve McDonough, 1989) ve (b) Kondrite (Boynton, 1984) normalize edilmiş iz element dağılım diyagramları.

Figure 7. Normalized trace element distribution diagrams of the samples (a) Primitive mantle (Sun and McDonough, 1989), and (b) Chondrite (Boynton, 1984). 


\section{TARTIŞMA}

\section{Fraksiyonel Kristallenme ve Asimilasyon (FC-AFC) Süreçleri}

Kayaçların oluşumunda önemli rol oynayan fraksiyonel kristallenme ve asimilasyon süreçleri, bazı ana ve iz elementlerin artan ve/veya azalan yönde değişimleri ile ortaya konabilmektedir. Örneğin, artan $\mathrm{SiO}_{2}$ içeriğine karşı $\mathrm{Al}_{2} \mathrm{O}_{3}$ ve $\mathrm{CaO}$ değişimleri (bkz. Şekil 6) plajiyoklas; MgO içeriğindeki azalmalar biyotit ve/veya amfibol; $\mathrm{Fe}_{2} \mathrm{O}_{3}{ }^{\top}$ 'da gözlenen azalmalar ise amfibol ve/veya $\mathrm{Fe}-\mathrm{Ti}$ oksit minerallerinin kristallenmesi ile ilişkilendirilebilir (Thirlwall vd., 1994). $\mathrm{K}_{2} \mathrm{O}$ içeriklerindeki hafif ve düzensiz pozitif dağılım ise K'lu feldispat birikimi ile; $\mathrm{Na}_{2} \mathrm{O}$ 'daki negatif yönseme ise plajiyoklasın ve kısmen de K'lu feldspatın fraksiyonel kristallenmesi ile kontrol edilmektedir. Benzer şekilde, $\mathrm{SiO}_{2}$ 'ye karşı $\mathrm{TiO}_{2}$ ve $\mathrm{P}_{2} \mathrm{O}_{5}$ değerlerinin azalması titanomanyetit ve apatitin kristallenmesi ile ilişkili olduğu söylenebilir. Tüm bu değişimler, Pamuktaş Plütonu kayaçlarının oluşumunda kesirli kristallenmenin baskın bir rol oynadığını göstermektedir. Benzer şekilde, ağır NTE ve Y içerikleri bakımında tüketilme de zirkon fraksiyonlaşmasının bir sonucu olarak değerlendirilebilir.

İz elementlerden Ba ve Sr elementlerindeki negatif yönsemeler, alkali feldspat ve plajiyoklas kristallenmesi ile bağlantılıdır (Rollinson, 1993; bkz. Şekil 6). Sr elementinin plajiyoklas minerallerinde Ca'un yerini alması nedeniyle, Ca bakımından zengin plajiyoklasların fraksiyonlaşması sonucu negatif bir ilişki gözlenmektedir. Benzer şekilde Rb, K'nın yerini almakta ve fraksiyonel kristallenme sırasında Kfeldispat, hornblend, biyotit gibi minerallerin bünyesine girebilmektedir. Biyotit mineralinin yapısına katılan $\mathrm{Nb}$ ve $\mathrm{Ba}$ elementlerinde ise yine negatif korelasyon gözlenmektedir (bkz. Şekil 6). Belirgin negatif Eu anomalisi, plutonun gelişiminde Kfeldispat \pm plajiyoklas fraksiyonlaşmasının etkili olduğunu ifade etmektedir. Th ve Ce elementlerinde ise biyotit ve zirkon minerallerindeki dağılım katsayılarının yüksek olmasından kaynaklı olarak pozitif anomali gözlenmektedir (ör., Mahood ve Hildreth, 1983). Netice itibariyle, incelenen örneklerin bazı ana ve iz element değişimlerinde gözlenen korelasyonlar, bu kayaçların gelişiminde plajiyoklas, K-feldispat, hornblend, biyotit, piroksen, apatit, zirkon ve manyetit gibi minerallerin fraksiyonlaşmasının etkili olduğunu ifade etmektedir. 
Pamuktaş Plütonu kayaçları yitim ve/veya kabuksal kirlenmeye işaret eden belirgin negatif $\mathrm{Nb}-\mathrm{Ta}$ ve güçlü pozitif $\mathrm{Pb}$ anomalisi (Taylor ve McLennan, 1985) göstermektedir (bkz. Şekil 7). Ayrıca, Ta, Th ve Ba gibi bazı element değişimlerinde gözlenen düzensiz dağılımlar granitik kayaçların gelişiminde etkili olan fraksiyonel kristallenmenin yanı sıra asimilasyon ve/veya magma karışımı olaylarının da etkili olduğunu göstermektedir. Kayaçların gelişiminde kıtasal kabuk asimilasyonu varlığı Pearce (1983)'ın Ta/Yb-Th/Yb diyagramı ile test edilmiştir (Şekil 8). Örneklerin yüksek $\mathrm{Th} / \mathrm{Yb}$ ve $\mathrm{Ta} / \mathrm{Yb}$ oranları göstermesi nedeniyle ortalama kıtasal kabuk değerine doğru bir yönseme gösterdikleri belirlenmiştir. Bu durum örnekleri oluşturan ana magmanın yitim bileşenlerince zenginleşmiş bir kaynaktan itibaren türediğini ve sonrasında ise fraksiyonel kristallenme ve kısmen asimilasyon süreçleri ile geliştiğini göstermektedir.

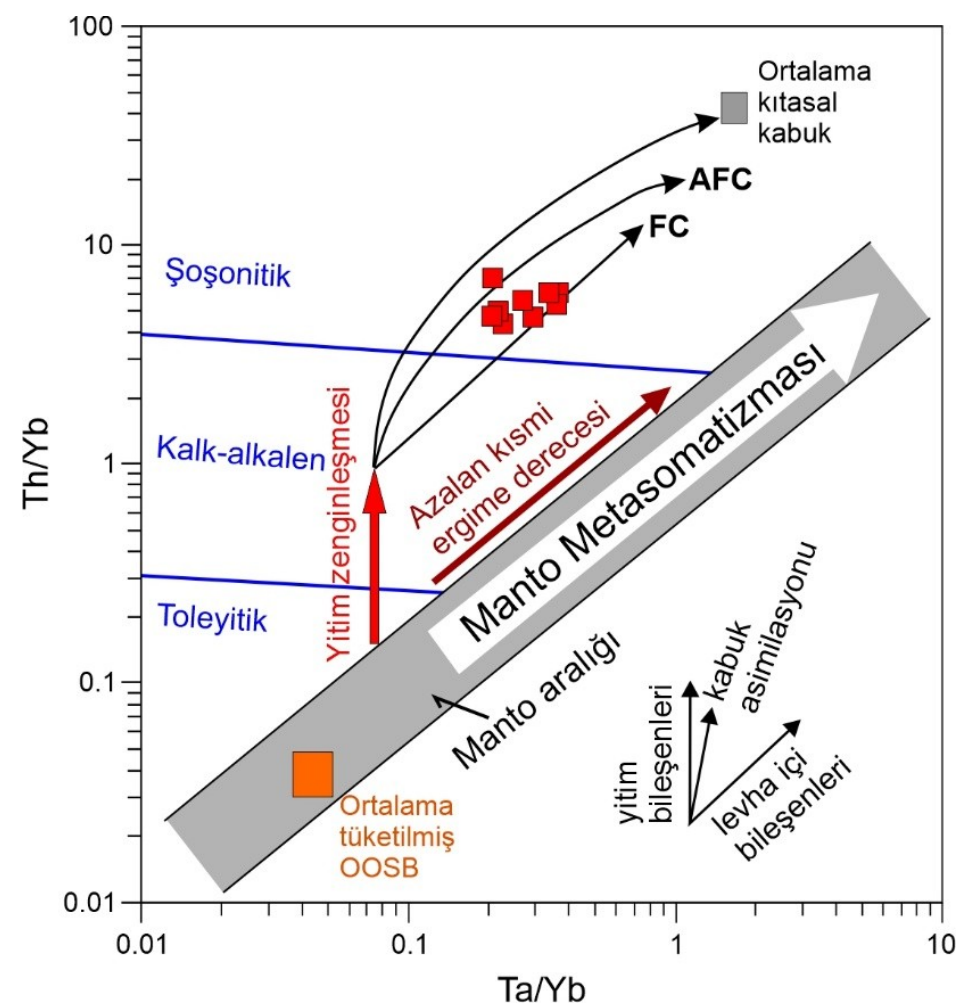

Şekil 8. Th/Yb-Ta/Yb diyagramı (Pearce, 1983). FC (fraksiyonel kristallenme), AFC (asimilasyon-fraksiyonel kristallenme), yitim zenginleşmesi ve manto metazomatizması yönsemeleri Pearce vd. (1990)'den alınmıştır.

Figure 8. Th/ $\mathrm{Yb}-\mathrm{Ta} / \mathrm{Yb}$ diagram of Pearce (1983). FC (fractional crystallization) and AFC (assimilation-fractional crystallization), subduction enrichment and mantle metasomatism trends from Pearce et al. (1990).

Nitekim, tüm örneklerin manto çizgisinden sapması, örneklerin yitim etkisiyle zenginleşmiş mantodan türemiş veya yükselimi sırasında kabuk tarafından kirlenmiş 
magmalardan itibaren oluştuğunu işaret etmektedir. Gözlenen bu sapma kaynak bölgesinde yitimle ilgili bir metasomatizma ile açıklanabileceği gibi, manto türevli ergiyiklere önemli ölçüde kabuksal ergiyik katılımına da işaret edebilir.

\section{Magma Karışımı}

Her iki felsik ve mafik magmaların homojen karışımları (magma mixing) özel mikroskobik dokular yardımıyla tanınabilmektedir (ör., Hibbard, 1991; 1995). Pamuktaş Plütonu'nu oluşturan ana magmada, magma karışımını işaret en önemli veriler, ana kayaçlar içerisinde gözlenen dengesizlik dokuları olup bunlar; elek dokulu, zonlu ve salınımlı zonlanma gibi dengesizlik dokuları gösteren plajiyoklaslar, iri plajiyoklas mineralleri üzerinde daha küçük plajiyoklas minerallerinin bulunması, bıçağımsı hornblendler, plajiyoklas, ortoklas ve mafik mineraller üzerinde daha küçük minerallerin oluşturmuş oldukları poikilitik dokulardır (bkz. Şekil 4). Bunun yanı sıra, intrüzif kayaçların oluşumunda magma karışımını daha ayrıntılı açıklayabilmek için, Maia de Hollanda vd. (2003) tarafından önerilen iz element diyagramları kullanılmıştır. Bir magmatik faaliyetin gelişimi sırasında, magma karışımı süreçleri gerçekleşmiş ise, $\mathrm{Ti} / \mathrm{Zr}$ oranına karşın $\mathrm{Rb} / \mathrm{Sr}$ oranı diyagramında hiperbolik bir değişim, $\mathrm{Ti} / \mathrm{Zr}$ oranına karşın $\mathrm{Sr} / \mathrm{Zr}$ oranında ise pozitif lineer değişim gözlenmesi gerekmektedir. $\mathrm{Ti} / \mathrm{Zr}$, $\mathrm{Rb} / \mathrm{Sr}$ ve $\mathrm{Sr} / \mathrm{Zr}$ oranları kullanılarak oluşturulan diyagramlarda ise Pamuktaş Plütonu örneklerinin söz konu değişimleri gösterdiği (Şekil 9a,b) ve kayaçların oluşumunda magma karışımı süreçlerinin meydana gelmiş olabileceği ortaya konmuştur.

\section{Kaynak Alan}

İntrüzif kayaçların sahip olduğu bileşimler farklı birçok petrojenetik mekanizmanın ürünü olarak meydana gelebilmektedir. Kayaçların jeokimyasal karakteristikleri, oluşumunda hangi mekanizmanın etkin olduğu hakkında bilgiler verebilmektedir. Granitik magmaların kökenine ilişkin farklı petrojenetik oluşum mekanizmaları önerilmiş olup bunlar genel olarak; (i) manto kökenli bazik magmalardan itibaren fraksiyonel kristallenme ile (ör., Li vd., 2009), (ii) mafik-ortaç kabuk kayaçlarının kısmi ergimesiyle (Roberts ve Clemens, 1993), (iii) manto ve kabuk kökenli mafik ve felsik magmaların karışımıyla (Ackerman vd., 2010) oluşabilmektedir. 
Pamuktaş Plütonu örneklerinin silika içerikleri nispeten geniş aralıkla $\left(\mathrm{SiO}_{2}=\% 66-75\right)$ değişmekte, ancak Mg\# değerleri 5 ile 31 arasında, yani oldukça düşük ve geniş bir aralıkda dağılım sergilemektedir. Bu değerler ilksel bir manto ergiyiği ile uyumsuz olup kayaçların bir manto kaynağının veya mafik-ortaç alt kabuğun kısmi ergimesinden (ör., Grove ve Donnelly-Nolan, 1986; Bacon and Druitt, 1988; Roberts ve Clemens, 1993; Şen ve Dunn, 1994) ya da alt kabuk ve manto türevli felsik ve mafik magmaların karışımı sonucu, kontaminasyona uğrayarak veya uğramadan, fraksiyonel kristallenme ile (Barbarin, 1999; Chen vd., 2003; Karslı vd., 2007; Yang vd., 2007) oluşmuş olabileceğini düşündürmektedir.
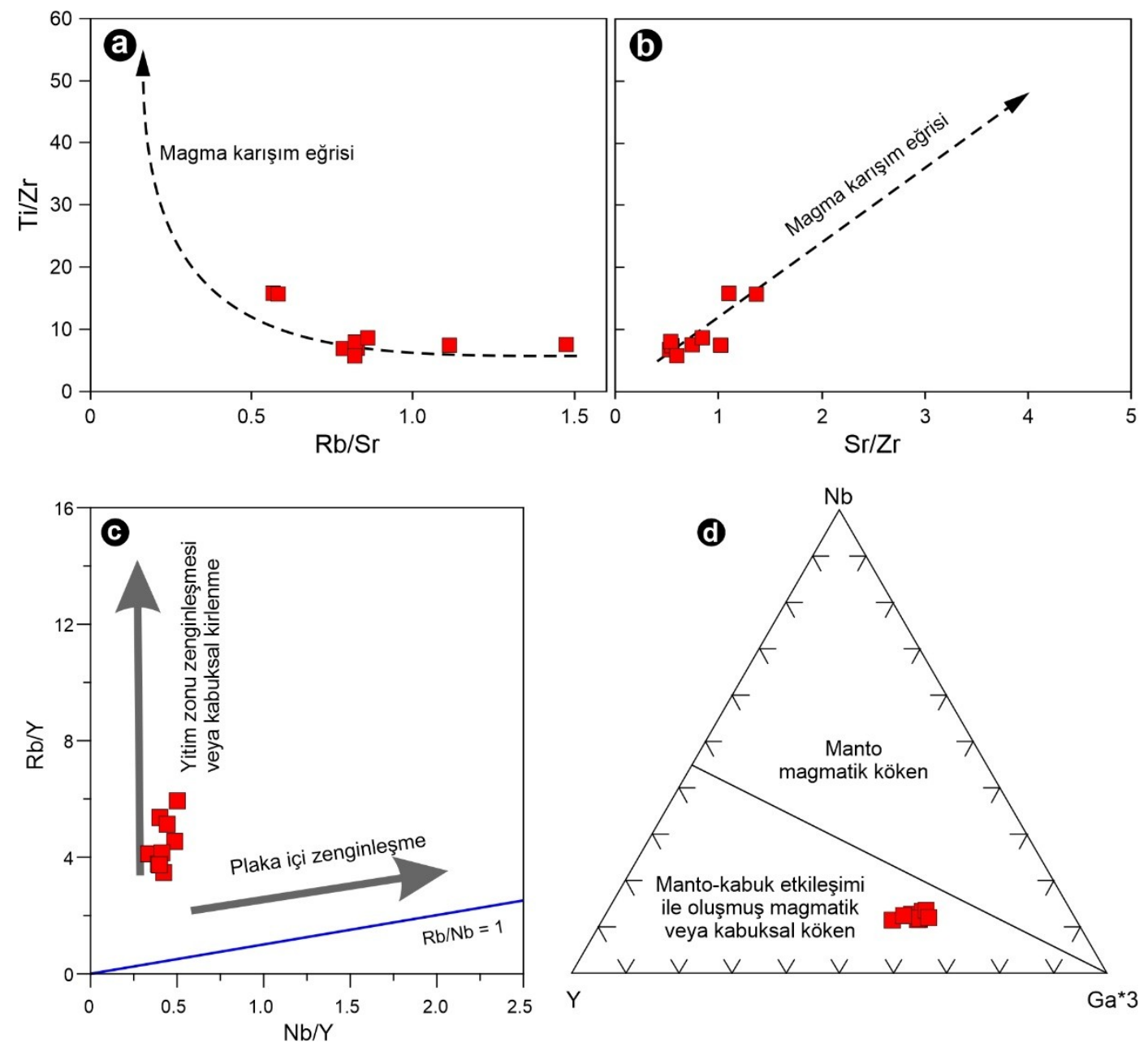

Şekil 9. Örneklerin; (a) Ti/Zr-Rb/Sr ve (b) Ti/Zr-Sr/Zr diyagramları. (c) $\mathrm{Rb} / \mathrm{Y}-\mathrm{Nb} / \mathrm{Y}$ ve (b) $\mathrm{Nb}$ Y-Ga*3 diyagramları (Eby, 1992).

Figure 9. (a) Ti/Zr-Rb/Sr and (b) Ti/Zr-Sr/Zr diagrams of the samples. (c) $R b / Y-N b / Y$ and (d) $\mathrm{Nb}-\mathrm{Y}-\mathrm{Ga}$ *3 diagrams (Eby, 1992).

$\mathrm{Y} / \mathrm{Nb}$ oranları ile kabuk $(\mathrm{Y} / \mathrm{Nb}>1.2)$ ve manto $(\mathrm{Y} / \mathrm{Nb}<1.2)$ kökenli granitoyidler birbirinden ayrılabilmektedir (Eby, 1992). Pamuktaş Plütonu örneklerinin Y/Nb 
oranları 1.2 ile 3.0 arasında değişmekte olup kabuk kökenini işaret etmektedir. Benzer şekilde, ortalama $\mathrm{Nb} / \mathrm{Ta}$ oranları mantodan türeyen magma için 17.5 ve kabuktan türeyen magma için de 11-12 arasındadır (Green, 1995). Pamuktaş Plütonu'na ait örneklerin Nb/Ta oranları 11.3-19.0 arasında olup, kabuk-manto kökeni göstermektedir. Örnekler çoğunlukla dar bir aralıkta değişen $\mathrm{Nb} / \mathrm{Y}$ oranlarıyla (0.330.85) nispeten yitim zeginleşmesi yönsemesi göstermektedir (Şekil 9c). Ayrıca, Eby (1992)'nin Nb-Y-Ga*3 üçgen diyagramına göre manto-kabuk etkileşimi ile oluşmuş magmatik veya kabuksal kökenli alanda yer aldıkları belirlenmiştir (Şekil 9d).

Yüksek-K'lu kalk-alkalen granitoyid kayaçlar üzerine yapılan deneysel çalışmalar, bu kayaçların farklı kabuksal kayaçların kısmı ergimesinden türeyebileceğini göstermiştir (ör., Roberts ve Clemens, 1993). Farklı türde kıtasal kabuk kayaçlarının, değişik ergime koşulları altında, kısmi ergimeler ile meydana gelmiş olan magmaların bileşimsel farklılıkları, ana oksit veya molar oranları esas alınarak açıklana bilmektedir (Patiño Douce, 1999). Pamuktaş Plütonu için oluşturulan diyagramlarda örneklerin genel olarak amfibolit-metagrovaklardan türeyen ergime alanında yer aldığı belirlenmiştir (Şekil 10a,b). Bu durum örneklerin I-tipi bir magmadan itibaren türemiş olduğunu işaret etmektedir. Th/U'ya karşı Th ve $U$ diyagramlarında ise (Şekil 10c,d) orta-alt kıtasal kabuktan türemiş ergimenin ürünleri olduğu ortaya konmuştur.

Tüm-kayaç bileşimleriyle hesaplanan zirkon doygunluk sıcaklıkları, granitik kayaçları oluşturan magmanın başlangıçtaki sıcaklıklarının tahmin edilmesinde yardımcı olabilmektedir. Bu termometre genellikle zirkona doymuş orta ila felsik magmalarda doğru sonuçlar verebilmektedir. Mineralojik ve jeokimyasal çalışmalar, örneklerin bol miktarda magmatik zirkon taneleri içerdiğini, zirkon içeriklerinin 262 ppm değerlerine kadar çıktığını ve dolayısıyla bu ergiyiklerin zirkon doygunluk için yeterli Zr içerdiğini işaret etmektedir. Bu durum, zirkon jeotermometresinin Pamuktaş Plütonu'nun ilksel magma sıcaklıklarını tahmin etmek için kullanılabileceğini göstermektedir. Örneklerin zirkon doygunluk sıcaklıkları Watson ve Harrison (1983), ve Boehnke vd. (2013) yöntemlerine göre tüm kayaç jeokimyasal analiz sonuçları kullanılarak hesaplanmıştır. İntrüzif magmanın maksimum veya minimum sıcaklığına ve ergiyiğin bu bileşenlerce doymuş veya doymamış olmasına bağlı olarak sıcaklık değerleri değişim gösterebilmektedir. Pamuktaş Plütonu kayaçlarının zirkon doygunluk sıcaklıkları $770-844^{\circ} \mathrm{C}$ (Watson ve Harrison, 1983) ve $730-814^{\circ} \mathrm{C}$ (Boehnke vd., 
2013) arasında hesaplanmıştır (Çizelge 3). Watson ve Harrison (1983)'a göre 4 örneğin $800^{\circ} \mathrm{C}$ 'nin altında, diğer örneklerin ise $800^{\circ} \mathrm{C}$ 'nin biraz üzerinde yer alması, Boehnke vd. (2013)'ne göre ise örneklerin büyük çoğunluğunun $800^{\circ}$ C'nin altında bir değer göstermesi, düşük ilksel magma sıcaklıklarını yansıtmaktadır. Bu durum ise Pamuktaş Plütonu örneklerinin orta-alt kıtasal kabuktan türemiş ergimenin ürünleri olduğunu desteklemektedir.
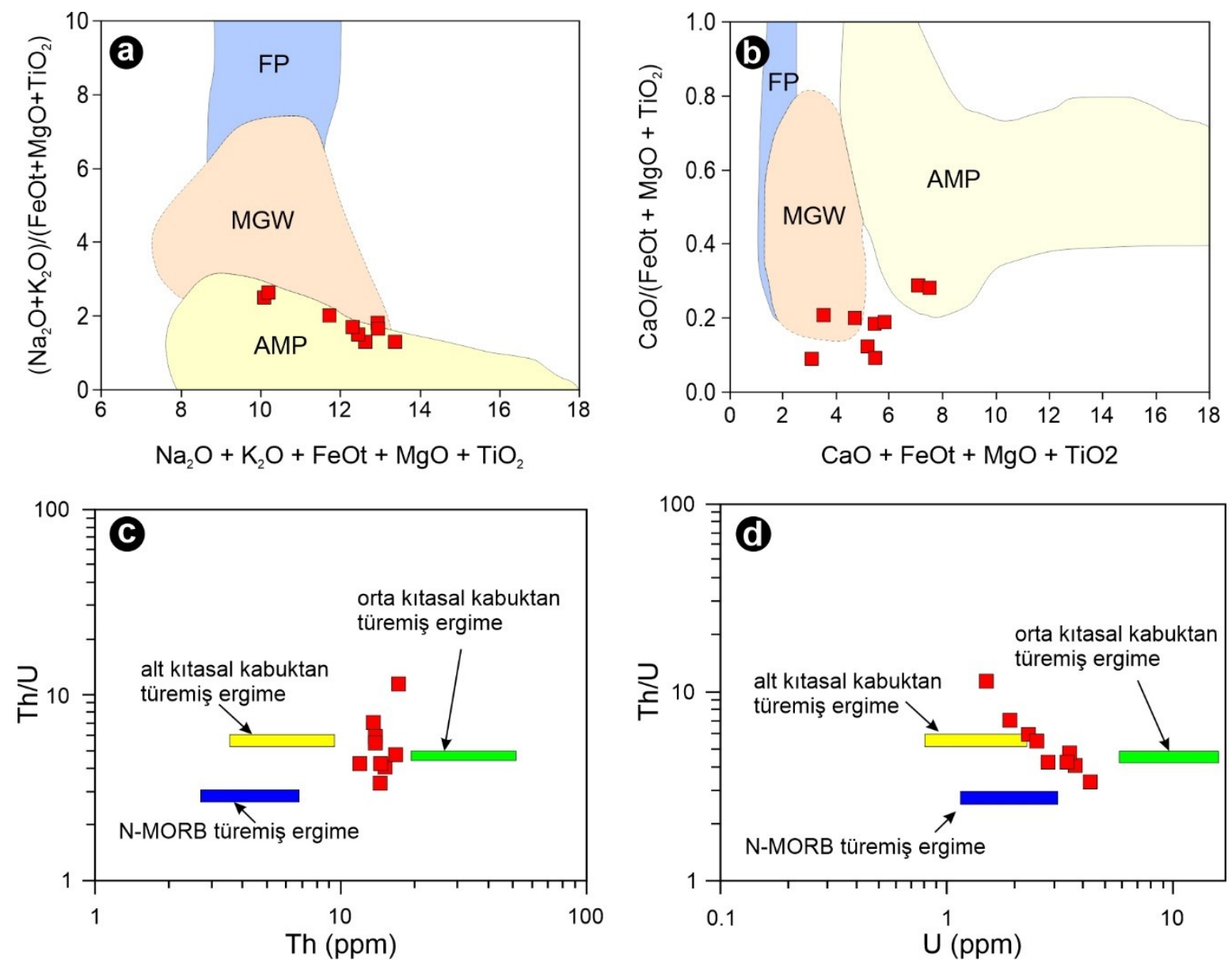

Şekil 10. (a) ve (b) Pamuktaş granitlerinin kimyasal kompozisyonları (ana hatları verilen alanlar, deneysel çalışmalarda çeşitli yığın bileşimlerin dehidrasyon ergimesi ile elde edilen kısmi ergiyiklerin bileşimlerini gösterir. MGW: Metagrovak, FP: Felsik pelit, AMP: Amfibolit. Veri kaynak alanları Patiño Douce, 1999'dan alınmıştır). (c) Th/U'ya karşı Th (ppm) ve (d) Th/U'ya karşı U (ppm) diyagramları (alt ve orta kıtasal kabuk değerleri Rudnick ve Gao, 2004 'ten alınmıştır).

Figure 10. (a) and (b) Chemical composition of the Pamuktaş granites (outlined fields denote compositions of partial melts obtained in experimental studies by dehydration melting of various bulk compositions. MGW: Metagreywackes, FP: Felsic pelites. AMP: Amphibolites. Data Sources from Patiño Douce, 1999). (c) Th/U vs Th (ppm) and (d) Th/U vs U (ppm) diagrams of the samples (lower and middle continental crust values are from Rudnick and Gao, 2004). 
İncelenen örneklerin ilksel mantoya normalize edilmiş çoklu iz element değişim diyagramındaki negatif $\mathrm{Nb}$, Ta ve $\mathrm{TiO}_{2}$ anomalileri ve $\mathrm{Rb}, \mathrm{Th}, \mathrm{K}_{2} \mathrm{O}, \mathrm{Sr}$, Ce ve $\mathrm{La}$ zenginleşmeleri ile yüksek BIYYE/YÇAE oranları, Pamuktaş Plütonu kayaçlarını oluşturan ana magmanın yitimle ilişkili farklı derecedeki akışkan ve ergiyik zenginleşmesi veya kabuk magma odalarındaki farklı ayrımlaşma ve asimilasyon yolları ile açıklanabilir. Bununla birlikte, örneklerin kondrite normalize edilmiş NTE diyagramında gözlenen zenginleşmeler, plütonun ana magmasının alt kıtasal kabuk ve zenginleşmiş litosferik manto ergiyiklerinden türediğini ve kıtasal magma odasında farklılaşarak yerleştiğini göstermektedir.

Çizelge 3. Pamuktaş Plütonu granitlerinin tüm kayaç zirkon jeotermometresi.

Table 3. Whole rock zircon geothermometer of granites of the Pamuktaş Pluton.

\begin{tabular}{lcccccc}
\hline Örnek No & $\mathbf{M}$ & $\mathbf{Z r}(\mathbf{p p m})$ & Zr.sat $^{1}$ & $\mathbf{T}_{\mathbf{z r}}\left({ }^{\circ} \mathbf{C}\right)^{\mathbf{2}}$ & Zr.sat $^{\mathbf{3}}$ & $\mathbf{T}_{\mathbf{z r}}\left({ }^{\circ} \mathbf{C}\right)^{4}$ \\
\hline AK6 & 1.35 & 241.8 & 100.3 & 827 & 168 & 789 \\
AK7 & 1.27 & 182.0 & 93.4 & 807 & 153 & 769 \\
P1 & 1.14 & 111.1 & 83.5 & 774 & 131 & 733 \\
P2 & 1.12 & 104.9 & 82.2 & 770 & 128 & 730 \\
P3 & 1.16 & 219.5 & 85.5 & 833 & 136 & 803 \\
P4 & 1.23 & 261.9 & 90.5 & 844 & 146 & 814 \\
P5 & 1.40 & 168.1 & 104.8 & 790 & 179 & 744 \\
P6 & 1.34 & 240.9 & 99.2 & 828 & 166 & 790 \\
P7 & 1.27 & 166.7 & 93.6 & 799 & 153 & 759 \\
\hline
\end{tabular}

$\mathrm{M}$ : katyonik oran [100x(Na+K+2Ca)/(Al.Si)]. 1: zirkon saturasyonu ve 2: zirkon jeotermometresi Watson ve Harrison (1983), 3: zirkon saturasyonu ve 4: zirkon jeotermometresi Boehnke vd. (2013)'e göre hesaplanmıştır.

\section{Tektonik Konum}

Pamuktaş Plütonu kayaçlarının oluşum ortamlarını ve tektono-magmatik özelliklerini belirleyebilmek amacıyla bazı ayırtman diyagramlar kullanılmıştır. Pearce vd. (1984) tarafından önerilen ve Rb (ppm)'a karşı $\mathrm{Y}+\mathrm{Nb}(\mathrm{ppm})$ değerlerinin kullanıldığı tektonik diyagramda tüm örneklerin volkanik yay granitleri (VAG) alanına düştüğü görülmektedir (Şekil 11a). Benzer durum Harris vd. (1986) tarafından önerilen Rb/30$\mathrm{Hf}-\mathrm{Ta}{ }^{*} 3$ üçgen diyagramda da gözlenmektedir (Şekil 11c). Ayrıca, plütona ait granitik kayaçların Thiéblemont ve Tégyey (1994)'in $\mathrm{Zr}$ (ppm)'a karşı $\mathrm{Nb}_{N} / \mathrm{Zr}_{\mathrm{N}}$ diyagramında büyük bir çoğunlukla "çarpışma ile ilişkili kalk-alkalen-peralkalen granitoyidler" alanında yer aldığı, iki örneğin ise yitimle ilişkili granitoyidler alanında dağılım gösterdiği ortaya konmuştur (Şekil 11b). Schandl ve Gorton (2002) tarafından önerilen $\mathrm{Th} / \mathrm{Hf}-\mathrm{Ta} / \mathrm{Hf}$ diyagramında örnekler aktif kıtasal kenar ortamını yansıtmaktadır (Şekil 11d). Magmatik, metamorfik ve sedimanter kayaçlarda 
elementlerin konsantrasyonları geniş aralıklarda değişmesine rağmen, Th/Hf oranlarının çok az değişiklik gösterdiği bilinmektedir (ör., McLennan ve Taylor, 1984).

Pamuktaş Plütonu kayaçlarının Martin (1986)'nın adakit ve normal yay serisi kayaçları ayırtman diyagramında (Şekil 12a) normal volkanik yay serisi alanında yer aldığı ve adakitik özellik göstermediği, Batchelor ve Bowden (1985) tarafından önerilen $\mathrm{La} / \mathrm{Yb}-\mathrm{Th} / \mathrm{Yb}$ diyagramında ise kıtasal kenar yayı alanında yer aldıkları gözlenmektedir (Şekil 12b). Bu veriler ışığında, granitik kayaçların tektonik olarak çarpışma sonrası oluştuğu ve volkanik yay ile ilişkili olduğu söylenebilir.
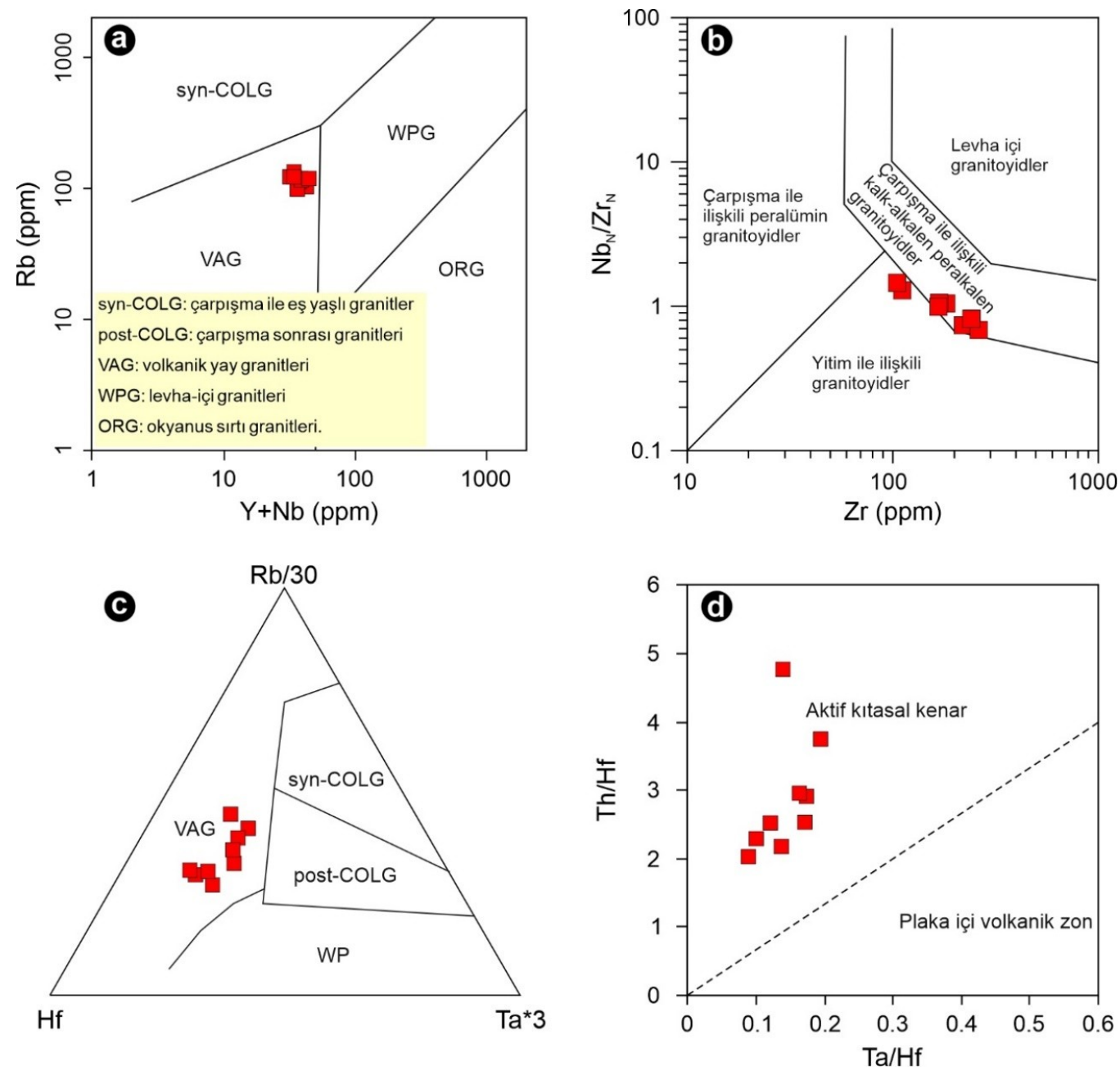

Şekil 11. (a) Rb (ppm)-Y+Nb (ppm) (Pearce vd., 1984), b) $\mathrm{Zr}$ (ppm)-Nb ${ }_{N} / \mathrm{Zr}_{\mathrm{N}}$ (Thiéblemont ve Tégyey, 1994), (c) Rb/30-Hf-Ta*3 (Harris vd., 1986) ve (d) Th/Hf-Ta/Hf (Schandl ve Gorton, 2002) diyagramları. Nb/Zr oranları Hoffman (1988)'ın ilksel manto değerine (Nb: 0.6175, Zr: 9.714) göre normalize edilmiştir.

Figure 11. (a) $R b$ (ppm)- $Y+N b$ (ppm) (Pearce et al., 1984), (b) $Z r$ (ppm)- $N b_{N} / Z r_{N}$ (Thiéblemont and Tégyey, 1994), (c) Rb/30-Hf-Ta*3 (Harris et al., 1986) and (d) Th/Hf-Ta/Hf (Schandl and Gorton, 2002) diagrams. Nb/Zr ratios are normalized according to Hoffman (1988) primitive mantle values (Nb: 0.6175, Zr: 9.714). 

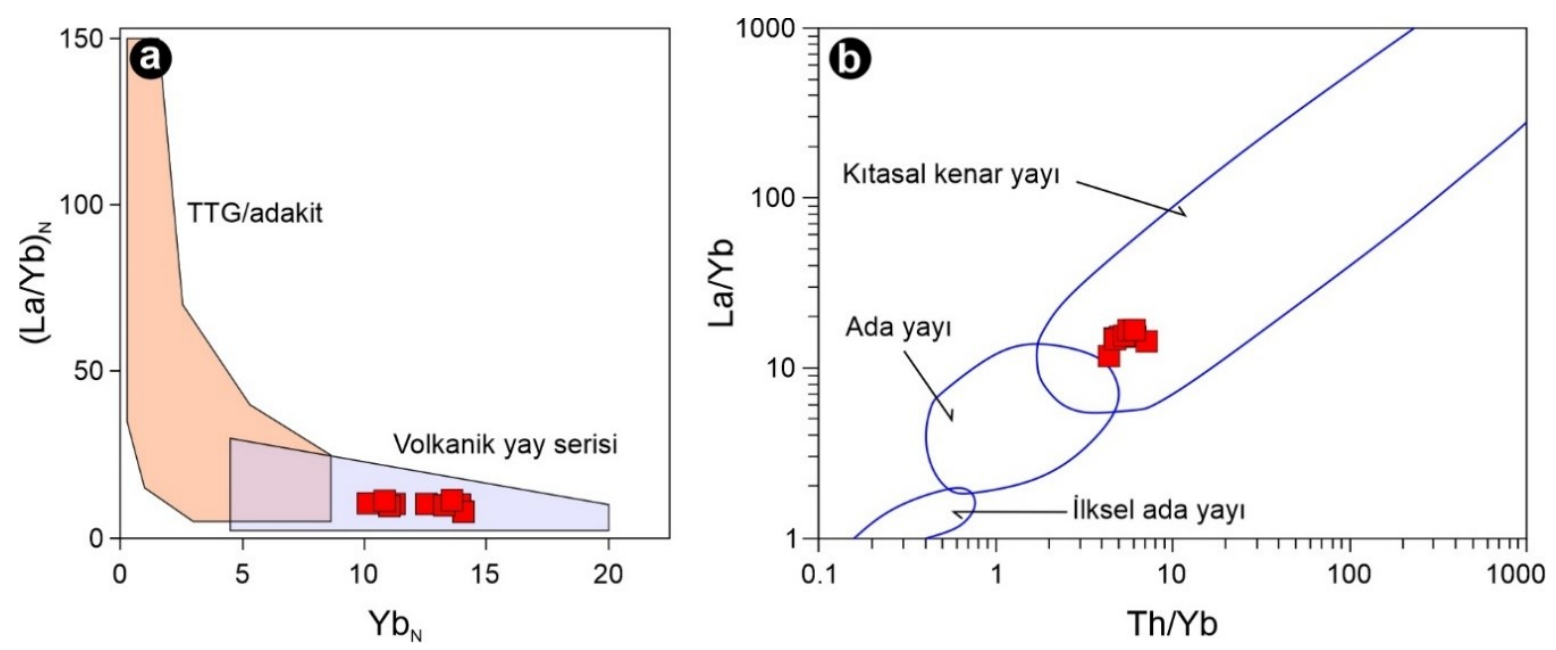

Şekil 12. (a) TTG/adakit ve normal volkanik yay serisi ayırtman diyagramı (Martin, 1986), (b) La/Yb'e karşı Th/Yb diyagramı (Batchelor ve Bowden, 1985). TTG: Tonalit-trondhjemitgranodiyorit.

Figure 12. (a) TTG/adakite vs normal volcanic arc series discrimination diagram (Martin, 1986), (b) La/Yb vs Th/Yb diagram (Batchelor ve Bowden, 1985). TTG: Tonalitetrondhjemite-granodiorite rocks.

\section{SONUÇLAR}

Bu çalışmada, Pamutaş (Bayburt, KD Türkiye) ve civarında yüzeyleme veren granitik kayaçların mineralojik, petrografik ve jeokimyasal veriler ışığında petrolojik karakteristikleri ortaya konmuş ve elde edilen sonuçlar ana hatları ile aşağıda özetlenmiştir:

- Karbonifer Pamuktaş Plütonu çalışma alanında Jura öncesi temeli temsil etmekte ve Alt-Orta Jura volkanoklastik ve volkanik kayaçlar ile Üst Jura-Alt Kretase kireçtaşları tarafından uyumsuz olarak örtülmektedir. Yaklaşık $5 \mathrm{~km}^{2}$ lik bir alanda yayılım gösteren birim, tek bir bileşimden oluşmayıp, başlıca granit/aplitik granit, granodiyorit ve kuvarslı mikrodiyorit türü kayaçlardan meydana gelmiştir.

- Kayaçların ana minerallerini açık renkli minerallerden kuvars, plajiyoklas ve ortoklas, ferromagnezyen minerallerden ise biyotit ve hornblend meydana getirmektedir. Bazı örneklerde opak mineraller, ikincil muskovit ve klorit mineralleri ile alterasyon ürünü olan serizitleşme, killeşme, karbonatlaşma ve silisleşmeler de izlenebilmektedir.

- Granitik kayaçlar peralümin karakterli, yüksek K'lu kalk-alkali ve şoşonitik bir afiniteye sahip olup I-tipi bir kaynaktan itibaren türemiştir. Kayaçların 
oluşumunda fraksiyonel (kesirli) kristallenme ve asimilasyon süreçleri etkili olmuş olup plajiyoklas, hornblend, biyotit, piroksen, apatit, zirkon ve manyetit gibi minerallerin fraksiyonlaşmasını işaret etmektedir.

- Bazı ana ve iz element değişimlerinde gözlenen korelasyonlar incelenen kayaçların düşük dereceli kısmi ergimeye uğradığını ve granitlerin gelişiminde plajiyoklas + K-feldispat + hornblend \pm biyotit fraksiyonlaşmasının etkili olduğunu göstermektedir. Kayaçların yitim etkisiyle zenginleşmiş mantodan türemiş veya yükselimi sırasında kabuk tarafından kirlenmiş magmalardan itibaren oluştuğunu işaret eden veriler elde edilmiştir.

- Kayaçlarda tespit edilen gerek dokusal gerekse bazı iz element değişimleri, oluşumunda magma karışımı süreçlerinin meydana gelmiş olabileceği göstermiştir. Kayaçların genel olarak amfibolit-metagrovaklardan türeyen bir ana magmadan itibaren oluştuğu ve orta-alt kıtasal kabuktan türemiş ergimenin ürünleri olduğu ortaya konmuştur. Elde edilen bulgular Pamuktaş Plütonu'nun ana magmasının alt-orta kıtasal kabuk ve zenginleşmiş litosferik manto ergiyiklerinden düşük dereceli kısmi ergime sonucu türediğini ve kıtasal magma odasında farklılaşarak yerleştiğini göstermektedir. Hesaplanan zirkon doygunluk sıcaklıkları ise, düşük ilksel magma sıcaklıklarını yansıtmakta olup, orta-alt kıtasal kabuktan türemiş ergimenin ürünleri olduğunu desteklemektedir.

- Pamuktaş Plütonu tektono-magmatik özellikleri bakımından volkanik yay granitlerine (VAG) benzerlik gösterdiği ve çoğunlukla "çarpışma ile ilişkili kalkalkalen-peralkalen granitoyidler" karakteri sergilediği belirlenmiştir. Pamuktaş Plütonu kayaçları adakitik özellik göstermeyip normal volkanik yay serisi özelliğini yansıtmaktadır. Bu veriler ışığında, granitik kayaçların tektonik olarak çarpışma sonrası oluştuğu ve volkanik yay ile ilişkili olduğu söylenebilir.

\section{KATKI BELIRTME}

Bu çalışma, ikinci yazarın Gümüşhane Üniversitesi, Fen Bilimleri Enstitüsü, Jeoloji Mühendisliği Anabilim Dalında yapmış olduğu yüksek lisans tez çalışmasından üretilmiştir. Ayrıca, Gümüşhane Üniversitesi Bilimsel Araştırma Projeleri (GÜBAP) Koordinatörlüğü'nce de desteklenmiştir (Proje No: 20.E3102.07.01). Makalenin inceleme ve değerlendirme aşamalarındaki değerli katkılarından dolayı Baş Editör 
Prof. Dr. Mehmet Tekin YÜRÜR, Teknik Editör Dr. Gülbanu TEKBULUT ve hakemlere şükranlarımızı sunarız.

\section{KAYNAKLAR}

Ackerman, L., Krňanská, M., Siebel, W. and Strnad, L. 2010. Geochemistry of the Drahotín and Mutěnín intrusions, West Bohemian shear zone, Bohemian massif: contrasting evolution of mantle-derived melts. Mineralogy and Petrology, 99, 185-199.

Ağar, Ü., 1977. Demirözü (Bayburt) ve Köse (Kelkit) Bölgesinin Jeolojisi. Doktora tezi, İ.Ü., Fen Fakültesi, İstanbul, 56.

Akın, H. 1979. Geologie Magmatismus und Lagerstaettenbildung im ostpontischen GebirgeTürkei aus der Sicht der Plattentektonik. Geologische Rundschau, 68, 253-283.

Akıncı, Ö.T., 1984. The Eastern Pontide volcano-sedimentary belt and associated massive sulphide deposits. In: J.E. Dixon and A.H.F. Robertson (eds.), The Geological Evolution of the Eastern Mediterranean. Geological Society, London, Special Publications, 17, 415-428.

Arslan, M., Tüysüz, N., Korkmaz, S., and Kurt, H., 1997. Geochemistry and Petrogenesis of the Eastern Pontide Volcanic Rocks, Northeast Turkey. Chemie der Erde Geochemistry, 57, 157-187.

Aydın, F., 2014. Geochronology, Geochemistry and Petrogenesis of the Maçka Subvolcanic Intrusions: Implications for the late Cretaceous Magmatic and Geodynamic Evolution of the Eastern Part of the Sakarya Zone, Northeastern Turkey. International Geology Review, 56 (10), 1246-1275.

Aydınçakır, E., 2016. Subduction-related Late Cretaceous high-K volcanism in the Central Pontides orogenic belt: Constraints on geodynamic implications. Geodinamica Acta, 28 (4), 379-411.

Aydınçakır, E., Gündüz, R. and Yücel, C., 2020. Emplacement conditions of magma(s) forming Jurassic plutonic rocks in Gümüşhane (Eastern Pontides, Turkey). Bulletin of the Mineral Research and Exploration, 162, 175-196.

Aydınçakır, E. and Şen, C., 2013. Petrogenesis of the post-collisional volcanic rocks from the Borçka (Artvin) area: Implications for the evolution of the Eocene magmatism in the Eastern Pontides (NE Turkey). Lithos, 172-173, 98-117. 
Bacon, C.R. and Druitt, T.H., 1988. Compositional Evolution of the Zoned CalcAlkaline Magma Chamber of Mount Mazama, Crater Lake, Oregon. Contribution to Mineralogy and Petrology, 98, 224-256.

Barbarin, B., 1999. A reviewof the relationships between granitoid types, their origins and their geodynamic environments. Lithos, 46, 605-626.

Batchelor, R. A. and Bowden, P., 1985. Petrogenetic interpretation of granitoid rocks series using multicationic parameters. Chemical Geology, 48, 43-55.

Bektaş, O. and Gedik, İ. 1988. A new formation with leucite-bearing shoshonitic volcanism in the Kop area (Everekhanları Formation) and its relationship with the evolution of the eastern Pontide arc, NE, Turkey. Geological Society of Turkey Bulletin, 31, 11-19.

Bergougnan, H., 1987. Etudes géologiques dans l'Est-anatolien: Mem. des Sci. De la Terre. Université Pierre et Marie Curie, Paris, p. 606 (Thèse de Doctorat d'Etat). Boehnke, P., Watson, E.B., Trail, D., Harrison, T.M. and Schmitt, A.K., 2013. Zircon saturation re-revisited. Chemical Geology, 351, 324-334.

Boynton, W.V., 1984. Cosmochemistry of the Rare Earth Elements; Meteorite Studies. In: Rare Earth Element Geochemistry. Henderson, P. (Eds), Elsevier Sci. Publ. Co., Amsterdam. 63-114.

Boztuğ, D., Erçin, A.İ., Kuruçelik, M.K., Göç, D., Kömür, İ. and İskenderoğlu, A., 2006. Geochemical characteristics of the composite Kaçkar batholith generated in a Neo-Tethyan convergence system, Eastem Pontides, Turkey. Journal of Asian Earth Sciences, 27, 286-302.

Chen, B., Jahn, B.M. and Zhai, M.G., 2003. Sr-Nd Isotopic Characteristics of the Mesozoic Magmatism in the Taihang-Yanshan Orogen, North China Craton, and Implications for Archean Lithosphere Thinning. Journal of the Geological Society London, 160, 963-970.

Çoğulu, E.,1975. Gümüşhane ve Rize Granitik Plütonlarının Mukayeseli Petrolojik ve Jeokronometrik Etüdü. Doçentlik Tezi, İTÜ Maden Mühendisliği, 186s. İstanbul.

Dokuz, A., Aydınçakır, E., Kandemir, R., Karslı, O., Siebel, W., Derman, A.S. and Turan, M., 2017. Late Jurassic Magmatism and Stratigraphy in the Eastern Sakarya Zone, Turkey: Evidence for the Slab Breakoff of Paleotethyan Oceanic Lithosphere. The Journal of Geology, 125(1), 1-31.

Dokuz, A. and Tanyolu, E., 2006. Gechemical Constraints on the Provenance, Mineral Sorting and Subaerial Weathering of Lower Jurassic and Upper Cretaceous Clastic Rocks from the Eastern Pontides, Yusufeli (Arvin), NE Turkey. Turkish Journal of Earth Sciences, 15, 181-209. 
Dokuz, A., 2011. A slab detachment and delamination model for the generation of Carboniferous high-potassium I-type magmatism in the Eastern Pontides, NE Turkey: Köse composite pluton. Gondwana Research, 19, 926-944.

Dokuz, A., Tanyolu, E. and Genç, S., 2006. A mantle- and a lower crust-derived bimodal suite in the Yusufeli (Artvin) area, NE Turkey: trace element and REE evidence for subduction-related rift origin of Early Jurassic Demirkent intrusive complex. International Journal of Earth Sciences, 95, 370-394.

Eby, G.N. 1992. Chemical subdivision of the A-type granitoids: petrogenetic and tectonic implications. Geology, 20, 641-644.

Eyüboğlu, Y., 2010. Late Cretaceous high-K volcanism in the eastern Pontide orogenic belt, and its implications for the geodynamic evolution of NE Turkey. International Geology Review, 52 (2/3), 142-186.

Göncüoğlu, M.C., 2010. Türkiye Jeolojisine Giriş: Alpin ve Alpin Öncesi Tektonik Birliklerin Jeodinamik Evrimi. MTA Genel Müdürlüğü, Monografi Serisi No: 5, 69 S., Ankara.

Green, T.H., 1995. Significance of $\mathrm{Nb} / \mathrm{Ta}$ as an indicator of geochemical processes in the crust-mantle system. Chemical Geology, 120, 347-359.

Grove, T.L. and Donnelly-Nolan, J.M., 1986. The Evolution of Young Silicic Lavas at Medicine Lake Volcano, California: Implications for the Origin of Compositional Gaps in Calc-Alkaline Series Lavas. Contributions to Mineralogy and Petrology, $92,281-302$.

Gülmez, F. ve Genç, S.C., 2015. Amasya Civarı Geç Kretase Yaşlı Ultrapotasik Volkaniklerinde Farklılaşma Süreçleri. Maden Teknik Arama Dergisi, 151, 153172.

Güven, İ.H., 1993. Doğu Karadeniz Bölgesi'nin 1/25.000 ölçekli jeolojisi ve komplikasyonu. MTA, Ankara.

Harris, N.B.W., Pearce, J.A. and Tindle, A.G. 1986. Geochemical characteristics of collision- zone magmatism. In: Coward M.P, Ries A.C. (eds.), Collision Tectonics. Geological Society of London Special Publication, 19, 67-81.

Hibbard, M.J., 1991. Textural anatomy of twelve magma mixed granitoid systems, in: Didier, J. and Barbarin, B. (Eds.), Enclaves and Granite Petrology, Developments in Petrology, 13, Elsevier, 431-444.

Hibbard, M.J., 1995. Petrography to Petrogenesis: Prentice Hall, New Jersey, 587 pp. 
Hoffman, A. W., 1988. Chemical differentiation of the Earth. The relationship between mantle, continental crust and oceanic crust. Earth and Planetary Science Letters, 90, 297-314.

Irvine, T.N. and Baragar, W.R.A., 1971. A guide to chemical classification of the common volcanic rocks. Canadian Journal of Earth Sciences, 8, 523-548.

Janoušek, V., Farrow, C.M. and Erban, V., 2006. Interpretation of whole-rock geochemical data in igneous geochemistry: introducing Geochemical Data Toolkit (GCDkit). Journal of Petrology, 47(6), 1255-1259.

Kandemir, R., and Yılmaz, C., 2009. Lithostratigraphy, facies and deposition environment of the Lower Jurassic Ammonitico Rosso Type Sediments (ARTS) in the Gumushane area, NE Turkey: Implications for the opening of the northern branch of the Neo-Tethys Ocean. Journal of Asian Earth Sciences, 34, 586-598.

Karslı, O., Aydin, F., Uysal, I., Dokuz, A., Kumral, M., Kandemir, R., Budakoglu, M. and Ketenci, M., 2018. Latest Cretaceous "A2-type" granites in the Sakarya Zone, NE Turkey: Partial melting of mafic lower crust in response to roll-back of Neo-Tethyan oceanic lithosphere. Lithos, 302-303, 312-328.

Karslı, O., Chen, B., Aydın, F. and Şen, C., 2007. Geochemical and Sr-Nd-Pb isotopic compositions of the Eocene Dölek and Sariçiçek Plutons, Eastern Turkey: Implications for magma interaction in the genesis of high-K calc-alkaline granitoids in a post-collision extensional setting. Lithos, 98, 67-96.

Karslı, O., Dokuz, A. and Kandemir, R., 2016. Subduction-related Late Carboniferous to Early Permian Magmatism in the Eastern Pontides, the Camlik and Casurluk plutons: Insights from geochemistry, whole-rock Sr-Nd and in situ zircon Lu-Hf isotopes, and U-Pb geochronology. Lithos, 266, 98-114.

Karslı, O., Dokuz, A. and Kandemir, R., 2017. Zircon Lu-Hf isotope systematics and $\mathrm{U}-\mathrm{Pb}$ geochronology, whole-rock $\mathrm{Sr}-\mathrm{Nd}$ isotopes and geochemistry of the early Jurassic Gokcedere pluton, Sakarya Zone-NE Turkey: a magmatic response to roll-back of the Paleo-Tethyan oceanic lithosphere. Contributions to Mineralogy and Petrology, 172, 31.

Karslı, O., Dokuz, A., Kaliwoda, M., Uysal, İ., Aydın, F., Kandemir, R. and Fehr, K-T., 2014. Geochemical fingerprints of Late Triassic calc-alkaline lamprophyres from the Eastern Pontides, NE Turkey: A key to understanding lamprophyre formation in a subduction-related environment. Lithos, 196-197, 181-197. 
Kaygusuz, A. and Aydınçakır, E., 2009. Mineralogy, whole-rock and $\mathrm{Sr}-\mathrm{Nd}$ isotope geochemistry of mafic microgranular enclaves in Cretaceous Dagbasi granitoids, Eastern Pontides, NE Turkey: Evidence of magma mixing, mingling and chemical equilibration. Chemie der Erde Geochemistry, 69, 247-277.

Kaygusuz, A. and Aydınçakır, E., 2011. U-Pb zircon SHRIMP ages, geochemical and Sr-Nd isotopic compositions of Cretaceous plutons in the eastern Pontides (NE Turkey): The Dağbaşı pluton. Neues Jahrbuch für Mineralogie - Abhandlungen, 188 (3), 211-233.

Kaygusuz, A., Arslan, M., Temizel, İ., Yücel, C. and Aydınçakır, E., 2021. U-Pb zircon ages and petrogenesis of the Late Cretaceous I-type granitoids in arc setting, Eastern Pontides, NE Turkey. Journal of African Earth Sciences, 174, 104040.

Kaygusuz, A. and Şen, C., 2011. Calc-alkaline I-Type plutons in the Eastern Pontides, NE Turkey: U-Pb zircon ages, geochemical and Sr-Nd isotopic compositions. Chemie der Erde Geochemistry, 71, 59-75.

Kaygusuz, A., 2020. Geochronological age relationships of Carboniferous Plutons in the Eastern Pontides (NE Turkey). Journal of Engineering Research and Applied Science, 9(1), 1299-1307.

Kaygusuz, A., Arslan, M., Siebel, W., Sipahi, F. and İlbeyli, N., 2012. Geochronological evidence and tectonic significance of Carboniferous magmatism in the southwest Trabzon area, eastern Pontides, Turkey. International Geology Review, 1776-1800.

Kaygusuz, A., Arslan, M., Sipahi, F. and Temizel, İ., 2016. U-Pb zircon chronology and petrogenesis of Carboniferous plutons in the northern part of the Eastern Pontides, NE Turkey: Constraints for Paleozoic magmatism and geodynamic evolution. Gondwana Research, 39, 327-346.

Kaygusuz, A., Sipahi, F., Illbeyli, N., Arslan. M., Chen, B. and Aydınçakır, E., 2013. Petrogenesis of the Late Cretaceous Turnagöl intrusion in the Eastern Pontides: Implications for magma genesis in the arc setting. Geoscience Frontiers, 4, 423438.

Keskin, İ., Korkmaz, S., Gedik, İ., Ateş, M., Gök, L., Küçümen, Ö. ve Erkal, T., 1989. Bayburt Dolayının Jeolojisi. MTA Rap. No: 8995,129s, Ankara.

Li, X.H., Li, W.X., Li, Z.X., Lo, C.H., Wang, J., Ye, M.F. and Yang, Y.H. 2009. Amalgamation between the Yangtze and Cathaysia Blocks in South China: constraints from SHRIMP U-Pb zircon ages, geochemistry and Nd-Hf isotopes of the Shuangxiwu volcanic rocks. Precambrian Research, 174, 117-128. 
Mahood, G. and Hildreth, W., 1983. Large partition coefficients for trace elements in high-silica rhyolites. Geochimica et Cosmochimica Acta, 47, 11-30.

Maia de Hollanda, M.H.B., Pimentel, M.M., Jardim de Sá, E.F., 2003. Paleoproterozoic subduction-related metasomatic signatures in the lithospheric mantle beneath NE Brazil: inferences from trace element and $\mathrm{Sr}-\mathrm{Nd}-\mathrm{Pb}$ isotopic compositions of Neoproterozoic high-K igneous rocks. Journal of South American Earth Sciences, 15, 885-900.

Martin, H., 1986. Effect of steeper Archean geothermal gradient on geochemistry of subduction-zone magmas. Geology, 14, 753-756.

McLennan, S.M. and Taylor, S.R., 1984. Archean Sedimentary Rocks and Their Relation to the Composition of the Archean Continental Crust, in Kröner, A., et al., (eds)., Archean Geochemistry Berlin, Springer-Verlag, 42-72.

McLennan, S.M., 1989. Rare Earth Elements in Sedimentary Rocks: Influence of Provenance and Sedimentary Processes, In: Lipin, B.R., MacKay, G.A. (Eds.), Geochemistry and Mineralogy of Rare Earth Elements. Mineralogical Society of America, 169-200.

Middlemost, E.A., 1994. Naming materials in the magma/igneous rock system. EarthScience Reviews, 37, 215-224.

Okay, A.İ. and Şahintürk, Ö., 1997. Geology of the Eastern Pontides, In: Robinson, A.G. (Eds), Regional and petroleum geology of the Black Sea and surrounding region. AAPG Bulletin, 68, 291-311.

Okay, A.İ. and Tüysüz, O., 1999. Tethyan Sutures of Northern Turkey. The Mediterranean Basin: Tertiary Extension within the Alpine Orogen. Geological Society, London, Special Publications, 156, 475-515.

Okay, A.I.., 2008. Geology of Turkey: A Synopsis. Anschnitt, 21, 19-42.

Patiño Douce, A.E., 1999. What do Experiments Tell us About the Relative Contributions of Crust and Mantle to the Origin of Granitic Magmas In: Castro, A., Fernandez, C., Vigneressese, J.L. (Eds.), Understanding Granites: Intergrating New and Classical Techniques. Geological Society of London, Special Publication, 168, 55-75.

Pearce, J.A. 1983. The Role of Sub-Continental Lithosphere in Magma Genesis at Destructive Plate Margins. In: Continental Basalts and Mantle Xenoliths, (eds): Hawkesworth, C.J., Norry, M.J., Shiva Publishing, Cheshire, 230-249. 
Pearce, J.A., Bender, J.F., De Long, S.E., Kidd, W.S.F., Low, P.J., Güner, Y., Şaroğlu, F., Yılmaz, Y., Moorbath, S. and Mitchell, J.J. 1990. Genesis of collision volcanism in eastern Anatolia Turkey. Journal of Volcanology and Geothermal Research, 44, 189-229.

Pearce, J.A., Haris, N.B.W. and Tindle, A.G., 1984. Trace element discrimination diagrams for the tectonic interpretation of granitic rocks. Journal of Petrology, 25, 956-983.

Peccerillo, A. and Taylor, S. R., 1976. Geochemistry of Eocene calc-alkaline volcanic rocks from the Kastamonu area, Northern Turkey. Contributions to Mineralogy and Petrology 58, 63-81.

Pelin, S., 1977. Alucra (Giresun) güneydoğu yöresinin petrol olanakları bakımından jeolojik incelemesi. KTÜ yayını, 87, 103.

Roberts, M.P. and Clemens, J.D., 1993. Origin of High-Potassium, Calcalkaline, IType Granitoids. Geology, 21, 825-828.

Rollinson, H.R., 1993. Using Geochemical Data: Evaluation, Presentation, Interpretation. Johhn Wiley \& Sons, New York, 352 p.

Rudnick, R.L. and Gao, S., 2004. Composition of The Continental Crust. Treatise on Geochemistry, 3, 1-65.

Saydam Eker, Ç., Akpınar, İ. and Sipahi, F., 2016. Organic geochemistry and element distribution in coals formed in Eocene lagoon facies from the Eastern Black Sea Region, NE Turkey. Turkish Journal of Earth Sciences, 25, 467-489.

Schandl, E.S. and Gorton, M.P., 2002. Application of High field Strength Elements to Discriminate Tectonic Settings in VMS Environments. Economic Geology, 97, 629-642.

Shand, S. J., 1943. Eruptive Rocks. Their Genesis, Composition, Classification, and Their Relation to Ore-Deposits with a Chapter on Meteorite. New York: John Wiley \& Sons.

Sipahi, F., Gücer, M.A. and Saydam Eker, Ç., 2020a. Geochemical composition of magnetite from different iron skarn mineralizations in NE Turkey: implication for source of ore forming fluids. Arabian Journal of Geosciences, 13(2), 70.

Sipahi, F., Gücer, M.A. and Sadıklar, M.B., 2020b. Nature of clays in Late Cretaceous dacitic rocks in the eastern Sakarya Zone (NE Turkey): A geochemical and isotopic approach. Turkish Journal of Earth Sciences, 29(6), 831-852. 
Sipahi, F., Gücer, M.A. ve Sadıklar, M.B., 2019. Zigana Dağı (Gümüşhane, KD Türkiye) Dayklarının Jeokimyası ve Jeolojik Anlamı. Yerbilimleri, 40 (3), 293325.

Sipahi, F., Kaygusuz, A., Saydam Eker, Ç., Vural, A. and Akpınar, İ., 2018. Late Cretaceous arc igneous activity: the Eğrikar Monzogranite example. International Geology Review, 60 (3), 382-400.

Sun, S. and McDonough, W.F., 1989. Chemical and Isotopic Systematics of Oceanic Basalt: Implications for Mantle Composition and Processes, In: A. D. Saunders, ve M.J. Norry, (eds.), Magmatism in the Ocean Basins. Geological Society London Special Publications, 42, 313-345.

Şen, C., Aydınçakır, E., Yağcıoğlu, U.C. ve Bak, T., 2019. Sakarya Zonunun Güney Kesiminde Yüzeylenen Geç Kretase Alkalen Volkanitlerinin Jeokimyasal Özelliklerinin Karşılaştırılması. Gümüşhane Üniversitesi Fen Bilimleri Enstitüsü Dergisi, 9(1), 1-15.

Şen, C. and Dunn, T., 1994. Dehydration melting of a basaltic composition amphibolites at 1.5 and $2.0 \mathrm{GPa}$ : implications for the origin of adakites. Contribution to Mineralogy and Petrology, 117, 394-409.

Şen, C., 2007. Jurassic volcanism in the Eastern Pontides: Is it rift related or subduction related? Turkish Journal of Earth Sciences, 16, 523-539.

Şengör, A.M.C. and Yılmaz, Y., 1981. Tethyan evolution of Turkey: a plate tectonic approach. Techtonophysics, 75, 181-241.

Taylor, S.R. and McLennan, S.M., 1985. The Continental Crust: Its Composition and Evolution. Blackwell Scientific Publications, Blackwell, Oxford, U.K., 312 p.

Thiéblemont, D. and Tégyey, M., 1994. Une discrimination géochimique des roches différenciées témoin de la diversité d'origine et de situation tectonique des magmas calco-alcalins. Comptes Rendus de l'Académie des Sciences, 319, 87 94.

Thirlwall, M.F., Smith, T.E., Graham, A.M., Theodorou, N., Hollings, P. and Davidson, J.P., 1994. High Field Strength Element Anomalies in Arc Lavas: Source or Processes. Journal of Petrology, 35, 819-838.

Topuz, G., Altherr, R., Kalt, A., Satır, M., Wemer, O. and Schwarz, W.H., 2004. Aluminous granulites from the Pulur complex, NE Turkey: a case of partial melting, efficient melt extraction and crystallization. Lithos, 72, 183-207. 
Topuz, G., Altherr, R., Schwarz, W.H., Dokuz, A. and Meyer, H.P., 2007. Variscan amphibolite-facies rocks from the Kurtoğlu metamorphic complex. Gümüşhane area, Eastern Pontides, Turkey. International Journal of Earth Sciences, 96, 861-873.

Topuz, G., Altherr, R., Wolfgang, S., Schwarz, W.H., Zack, T., Hasanözbek, A., Mathias, B., Satır, M., and Şen C., 2010. Carboniferous high-potassium I-type granitoid magmatism in the Eastern Pontides: The Gümüşhane pluton (NE Turkey). Lithos, 116, 92-110.

Ustaömer, T. and Robertson, H.F.A, 2010. Late Paleozoic-Early Cenozoic development of the Eastern Pontides (Artvin area), Turkey: stages of closure of Tethys along the southern margin of Eurasia. Geological Society, London, Special Publications, 340, 281-327.

Ustaömer, T., Robertson, A.H.F., Ustaömer, P.A., Gerdes, A. and Peytcheva, I., 2013. Constraints on Variscan and Cimmerian magmatism and metamorphism in the Pontides (Yusufeli-Artvin area), NE Turkey from U-Pb dating and granite geochemistry. In Robertson, A.H.F., Parlak, O., Ünlügenç, U.C. (eds). Geological Development of Anatolia and the Easternmost Mediterranean Region. Geological Society, London. Special Publications, 372, 49-74.

Watson, E.B. and Harrison, M., 1983. Zircon saturation revisited: temperature and composition effects in a variety of crustal magma types. Earth and Planetary Science Letters, 64, 295-304.

Yang, J.H.., Fu, Y., Wu, F.Y., Wilde, S.A., Xie, L.W., Yang, Y.H. and Liu, X.M., 2007. Tracing Magma Mixing in Granite Genesis: in Situ U-Pb Dating and Hf-Isotope Analysis of Zircons. Contributions to Mineralogy and Petrology, 153, 177-190.

Yılmaz, Y., Tüysüz, O., Yiğitbaş, E., Genc, Ş.C. and Şengör, A.M.C., 1997. Geology and tectonics of the Pontides. In: Robinson, A.G. (eds), regional and petroleum geology of the Black Sea and surrounding region. AAPG Memoirs. 68, 183-226.

Yücel, C., Arslan, M., Temizel, İ. and Abdioğlu Yazar, E., 2014. Volcanic facies and mineral chemistry of Tertiary volcanics in the northern part of the Eastern Pontides northeast Turkey implications for pre eruptive crystallization conditions and magma chamber processes. Mineralogy and Petrology, 108 (3), 439-467. 